\title{
A global scale mechanistic model of photosynthetic capacity (LUNA V1.0)
}

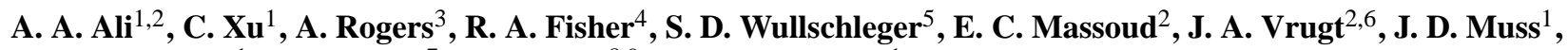 \\ N. G. McDowell ${ }^{1}$, J. B. Fisher ${ }^{7}$, P. B. Reich ${ }^{8,9}$, and C. J. Wilson ${ }^{1}$ \\ ${ }^{1}$ Earth and Environmental Sciences Division, Los Alamos National Laboratory, Los Alamos, New Mexico, USA \\ ${ }^{2}$ Department of Civil and Environmental Engineering, University of California Irvine, Irvine, California, USA \\ ${ }^{3}$ Environmental and Climate Sciences Department, Brookhaven National Laboratory, Upton, New York, USA \\ ${ }^{4}$ Climate and Global Dynamics, National Center for Atmospheric Research, Boulder, Colorado, USA \\ ${ }^{5}$ Climate Change Science Institute, Environmental Sciences Division, Oak Ridge National Laboratory, \\ Oak Ridge, Tennessee, USA \\ ${ }^{6}$ Department of Earth System Science, University of California Irvine, Irvine, California, USA \\ ${ }^{7}$ Jet Propulsion Laboratory, California Institute of Technology, Pasadena, California, USA \\ ${ }^{8}$ Department of Forest Resources, University of Minnesota, St. Paul, Minnesota, USA \\ ${ }^{9}$ Hawkesbury Institute for the Environment, University of Western Sydney, Penrith, New South Wales, Australia
}

Correspondence to: C. Xu (xuchongang@gmail.com)

Received: 8 July 2015 - Published in Geosci. Model Dev. Discuss.: 10 August 2015

Revised: 12 December 2015 - Accepted: 6 January 2016 - Published: 12 February 2016

\begin{abstract}
Although plant photosynthetic capacity as determined by the maximum carboxylation rate (i.e., $V_{c, \max 25}$ ) and the maximum electron transport rate (i.e., $J_{\max 25}$ ) at a reference temperature (generally $25^{\circ} \mathrm{C}$ ) is known to vary considerably in space and time in response to environmental conditions, it is typically parameterized in Earth system models (ESMs) with tabulated values associated with plant functional types. In this study, we have developed a mechanistic model of leaf utilization of nitrogen for assimilation (LUNA) to predict photosynthetic capacity at the global scale under different environmental conditions. We adopt an optimality hypothesis to nitrogen allocation among light capture, electron transport, carboxylation and respiration. The LUNA model is able to reasonably capture the measured spatial and temporal patterns of photosynthetic capacity as it explains $\sim 55 \%$ of the global variation in observed values of $V_{\mathrm{c}, \max 25}$ and $\sim 65 \%$ of the variation in the observed values of $J_{\max 25}$. Model simulations with LUNA under current and future climate conditions demonstrate that modeled values of $V_{\mathrm{c}, \max 25}$ are most affected in high-latitude regions under future climates. ESMs that relate the values of $V_{\mathrm{c}, \max 25}$ or $J_{\max 25}$ to plant functional types only are likely to substantially overestimate future global photosynthesis.
\end{abstract}

\section{Introduction}

Photosynthesis is one of the major components of the ecosystem carbon cycle (Canadell et al., 2007; Sellers et al., 1997) and is thus a key ingredient of Earth system models (ESMs) (Block and Mauritsen, 2013; Hurrell et al., 2013). Most ESMs are based on the photosynthesis model developed by Farquhar et al. (1980). The maximum carboxylation rate scaled to $25^{\circ} \mathrm{C}$ (i.e., $V_{\mathrm{c}, \max 25} ; \mu \mathrm{mol} \mathrm{CO} \mathrm{CO}^{-2} \mathrm{~s}^{-1}$ ) and the maximum electron transport rate scaled to $25^{\circ} \mathrm{C}$ (i.e., $J_{\max 25}$; $\mu$ mol electron $\mathrm{m}^{-2} \mathrm{~s}^{-1}$ ) in the model have been generally accepted as the main proxies of photosynthetic capacity. $V_{\mathrm{c}, \max 25}$ and $J_{\max 25}$ are key biochemical parameters in photosynthesis models as they control the carbon fixation process (Farquhar et al., 1980). Large spatial and temporal variations in estimates of the gross primary productivity exist across ESMs (Schaefer et al., 2012), which have been partly attributed to uncertainties in $V_{\mathrm{c}, \max 25}$ (Bonan et al., 2011). Accurate estimates of $V_{\mathrm{c}, \max 25}$ and $J_{\max 25}$ are of paramount importance to simulate the gross primary productivity as errors in these two entities may be exacerbated when upscaling from leaf to ecosystem level (Hanson et al., 2004).

Many studies have demonstrated that it is particularly difficult to predict accurately the global scale variations in $V_{\mathrm{c}, \max 25}$ and $J_{\max 25}$ (Bonan et al., 2011; Rogers, 2014). 
One important reason that contributes to this rather poor predictability is a lack of understanding of the processes that control the values of $V_{\mathrm{c}, \max 25}$ and $J_{\max 25}$ (Maire et al., 2012; Xu et al., 2012) despite the fact that $V_{\mathrm{c}, \max 25}$ has been measured and studied more extensively than most other photosynthetic parameters (Kattge and Knorr, 2007; Leuning, 1997; Wullschleger, 1993). Many empirical studies have shown that $V_{\mathrm{c}, \max 25}$ and $J_{\max 25}$ (or field-based surrogates) correlate with leaf nitrogen content (Medlyn et al., 1999; Prentice et al., 2014; Reich et al., 1998; Ryan, 1995; Walker et al., 2014). Therefore, a constant relationship between the leaf nitrogen content and $V_{\mathrm{c}, \max 25}$ or $J_{\max 25}$ is commonly utilized by many ecosystem models (Bonan et al., 2003; Haxeltine and Prentice, 1996; Kattge et al., 2009). However, the relationship between leaf nitrogen content, $V_{\mathrm{c}, \max 25}$ and $J_{\max 25}$ varies with light intensity, temperature, nitrogen availability and the atmospheric $\mathrm{CO}_{2}$ concentration (Friend, 1991; Reich et al., 1995; Ripullone et al., 2003). Thus, the presumed relationship between $V_{\mathrm{c}, \max 25}, J_{\max 25}$ and leaf nitrogen content might introduce significant simulation biases of future photosynthetic rates, which in turn may also affect predictions of the downstream carbon cycle and other climate processes that are dependent on the modeled photosynthetic rates (Bonan et al., 2011; Knorr and Kattge, 2005; Rogers, 2014).

To better describe the relationship between photosynthetic capacity and its driving environmental conditions, we have developed a global scale mechanistic model of leaf utilization of nitrogen for assimilation (LUNA). This model takes into explicit consideration the key environmental variables including temperature, radiation, humidity, $\mathrm{CO}_{2}$ concentration and day length to explain the complex dependencies between leaf nitrogen, $V_{\mathrm{c}, \max 25}$ and $J_{\max 25}$. Using an optimality hypothesis, the LUNA model allocates leaf nitrogen to different processes, thereby predicting the values of $V_{\mathrm{c}, \max 25}$ and $J_{\max 25}$ under different environmental conditions. We estimate the parameters of LUNA by fitting the model against globally distributed observations of $V_{\mathrm{c}, \max 25}$ and $J_{\max 25}$. We then use the calibrated LUNA model to assess the impacts of future climate change on photosynthesis by estimating the summer-season net photosynthetic rate using LUNA's predicted values of $V_{\mathrm{c}, \max 25}$ and $J_{\max 25}$ under historic and future climate conditions.

\section{Methodology}

\subsection{Overview}

The LUNA model (version 1.0) is based on the nitrogen allocation model developed by Xu et al. (2012), which optimizes nitrogen allocated to light capture, electron transport, carboxylation and respiration. Xu et al. (2012) considered a few model assumptions to derive the optimized nitrogen distributions, including (i) storage nitrogen is allocated to meet requirements to support new tissue production; (ii) respira- tory nitrogen is equal to the demand implied by the sum of maintenance respiration and growth respiration; and (iii) light capture, electron transport and carboxylation are colimiting to maximize photosynthesis. The model of $\mathrm{Xu}$ et al. (2012) has been tested for three different sites only without global-scale calibration of its parameters. Here, we expand the work of $\mathrm{Xu}$ et al. (2012) by using a global data set of observations of photosynthetic capacity to derive accurate values of the model parameters and by incorporation of several refinements to support global-scale prediction of $V_{\mathrm{c}, \max 25}$ and $J_{\max 25}$. Specifically, this revised model considers additional environmental variables such as day length and humidity, and honors variations in the balance between the light-limited electron transport rate and the Rubisco-limited carboxylation rate. We use an efficient Markov chain Monte Carlo simulation approach, the Differential Evolution Adaptive Metropolis algorithm $\left(\operatorname{DREAM}_{(\mathrm{ZS})}\right)$ (Laloy and Vrugt, 2012; Vrugt et al., 2008, 2009), to fit the nitrogen allocation model to a large data set of observed $V_{\mathrm{c}, \max }$ and $J_{\max }$ values collected across a wide range of environmental gradients (Ali et al., 2015). After model fitting, sensitivity analyses are performed to gauge the response of the model to changes in its parameter values and the key environmental drivers including temperature, photosynthetic active radiation, day length, relative humidity and atmospheric $\mathrm{CO}_{2}$ concentration. Finally, mean summer-season $V_{\mathrm{c}, \max 25}$ and $J_{\max 25}$ values and their impacts on net photosynthesis are estimated for the globe, using climate projections from the Community Climate System Model (CCSM) (Gent et al., 2011).

\subsection{Model description}

The structure of the LUNA model is based on $\mathrm{Xu}$ et al. (2012), where the leaf nitrogen is divided into four different pools including structural nitrogen, photosynthetic nitrogen, storage nitrogen and respiratory nitrogen. We assume that plants optimize their nitrogen allocation to maximize the net photosynthetic carbon gain, defined as the gross photosynthesis $(A)$ minus the maintenance respiration for photosynthetic enzymes $\left(R_{\mathrm{psn}}\right)$, under given environmental conditions and a leaf nitrogen use strategy as determined by the parameters of the LUNA model. The model includes the following four unitless parameters: (1) $J_{\operatorname{maxb} 0}$, which specifies the baseline proportion of nitrogen allocated for electron transport rate; (2) $J_{\operatorname{maxb} 1}$, which determines response of electron transport rate to light; (3) $t_{\mathrm{c}, j 0}$, which defines the baseline ratio of Rubisco-limited rate to light-limited rate; and (4) $H$, which determines the response of electron transport rate to relative humidity. The LUNA model predicts the values of $V_{\mathrm{c}, \max 25}$ and $J_{\max 25}$ based on the optimal amounts of nitrogen allocated for carboxylation and electron transport. The model inputs are area-based leaf nitrogen content, leaf mass per unit leaf area and the driving environmental conditions including temperature, $\mathrm{CO}_{2}$, radiation, relative humidity and day length. 
It is important to stress here that the outcome of the optimality concept used in LUNA is conditional on the plant's nitrogen use strategies built into the model. Thus, it is possible that the optimal values of $V_{\mathrm{c}, \max 25}$ and $J_{\max 25}$ predicted by the LUNA model for future climate conditions could produce lower values of the net photosynthetic carbon gain than fixed values of $V_{\mathrm{c}, \max 25}$ and $J_{\max 25}$ without the use of a nitrogen use strategy. An example of this is shown in Fig. S1 in the Supplement, where the net photosynthetic carbon gain pertaining to the optimal nitrogen allocations predicted by the LUNA model for the elevated temperature is lower than its counterpart derived from a fixed nitrogen allocation for the ambient temperature. A complete description of the LUNA model and the associated optimality hypothesis and algorithms appears in Appendix A. This optimality approach is introduced and tested by Xu et al. (2012) for only three different sites, and here we evaluate its usefulness and applicability at the global scale with improvements to account for largescale variability. Optimality approaches are important tools for land surface models because they provide testable hypotheses for specific plant functions (Dewar, 2010; Franklin et al., 2012; Schymanski et al., 2009; Thomas and Williams, 2014).

\subsection{Data and temperature response functions}

Details of data collection are reported in Ali et al. (2015). Specifically, we conducted an exhaustive literature search with Google Scholar to obtain publications that contained the words $V_{\mathrm{c}, \max }, J_{\max }$, maximum carboxylation rate or maximum electron transport rate. To rapidly subset the most appropriate and relevant publications, we use simultaneously the wording leaf nitrogen content, leaf mass per area or specific leaf area. Individual values of $V_{\mathrm{c}, \max }, J_{\max }$, area-based leaf nitrogen content $\left(\mathrm{LNC}_{\mathrm{a}} ; \mathrm{g} \mathrm{N} \mathrm{m}^{-2}\right.$ leaf) and leaf mass per unit leaf area (LMA; g dry mass $\mathrm{m}^{-2}$ leaf) are then obtained by digitizing the experimental data depicted graphically in the selected papers. We use all of the data from Ali et al. (2015) with the exception of one study that collected seasonal data on $V_{\mathrm{c}, \max }$ and $J_{\max }$ during a prolonged drought (Xu and Baldocchi, 2003), as the LUNA model does not take into consideration the potential enzyme deterioration due to water stress but rather simulates only the optimal nitrogen allocation based on monthly climate conditions. This resulted in a data set of 766 observations of $V_{c, \max }$ and 643 data points of $J_{\max }$ ranging from the tropics to the arctic with a total of 125 species. The data include evergreen and deciduous species from arctic, boreal, temperate and tropical areas at different times of the year and from various canopy locations (Fig. S2).

To allow comparisons of $V_{\mathrm{c}, \max }$ and $J_{\max }$ data collected at different temperatures, we first standardize our data to a common reference temperature $\left(25^{\circ} \mathrm{C}\right)$. To do this, we employ temperature response functions (TRFs) for $V_{\mathrm{c}, \max }$ and $J_{\max }$. Because of issues related to the possibility of acclimation to temperature, there is not yet scientific consensus on which TRF to use (Yamori et al., 2006). Therefore, we use two alternative temperature response functions to evaluate the potential impact of our selection of the TRFs on the outcome of our analysis. The first temperature response function (TRF1) uses the formula of Kattge and Knorr (2007), which accounts empirically for the potential of thermal acclimation to growth temperature. Following the Community Land Model version 4.5 , the growth temperature is constrained between 11 and $35^{\circ} \mathrm{C}$ (Oleson et al., 2013) to limit the extent of acclimation to growth temperatures found in the calibration data set. The second temperature response function (TRF2) does not consider the thermal acclimation by fixing the acclimation coefficients in TRF1 (Kattge and Knorr, 2007). Please refer to Appendix B for details on TRF1 and TRF2 used herein.

Because the LUNA model is based on the $C_{3}$ photosynthetic pathway, in this study, we only consider $\mathrm{C}_{3}$ species. Typically, plant species are grouped into several simple plant functional types (PFTs) in ESMs because of computational limitations and gaps in ecological knowledge. The LUNA model does not differentiate among the PFTs of $\mathrm{C}_{3}$ species due to a limited coverage of environmental conditions for individual PFTs. Thus, a single set of parameter estimates is used for the PFTs of all $\mathrm{C}_{3}$ species.

\subsection{Parameter estimation}

The four parameters of LUNA are difficult to measure directly in the field. In this study, we estimate their values by fitting our model against observations of $V_{\mathrm{c}, \max 25}$ and $J_{\max 25}$ using the DREAM $(\mathrm{ZS})$ algorithm (Vrugt et al., 2008, 2009; Laloy and Vrugt, 2012). This method uses differential evolution as a genetic algorithm for population evolution with a Metropolis selection rule to decide whether candidate points should replace their parents or not. This simple Markov chain Monte Carlo (MCMC) method exhibits excellent sampling efficiencies on a wide range of model calibration problems, including multimodal and high-dimensional search problems. A detailed description of $\operatorname{DREAM}_{(\mathrm{ZS})}$ appears in Vrugt et al. (2008, 2009) and Laloy and Vrugt (2012) and interested readers are referred to these publications for further details. Uniform prior parameter distributions are used to constrain the potential parameter values and the Gaussian likelihood function is used to quantify the distance between the modeled $V_{\mathrm{c}, \max 25}$ and $J_{\max 25}$ values and their observed counterparts. Convergence plots of the DREAM $(Z S)$ sampled LUNA parameters to the posterior distribution are presented in Figs. S3 and S4.

\subsection{Model evaluations}

In this study, two different goodness-of-fit metrics are used to quantify the performance of the LUNA model against the $V_{\mathrm{c} \text {, max }}$ and $J_{\max }$ data. These are the coefficient of determination $\left(r^{2}\right)$ (Whitley et al., 2011) and the model efficiency 
(ME) (Whitley et al., 2011). The $r^{2}$ metric ranges between 0 and 1 and measures how much of the observed dispersion of $V_{\mathrm{c}, \max }$ or $J_{\max }$ is explained by the model. A related metric, the model efficiency is calculated using

$\mathrm{ME}=1-\frac{\sum\left(y_{i}-\hat{y}_{i}\right)^{2}}{\sum\left(y_{i}-\bar{y}\right)^{2}}$,

where $y_{i}$ and $\hat{y}_{i}$ denote the observed and LUNA-simulated values, respectively, and $\bar{y}$ signifies the mean of the observations. This metric measures the proportion of the variance in $V_{\mathrm{c}, \max }$ or $J_{\max }$ explained by the $1: 1$ line between model predictions and observations (Mayer and Butler, 1993; Medlyn et al., 2005). The ME ranges between 0 and 1 , where a ME of unity corresponds to a perfect match between the modeled and measured data and a ME of zero indicates that the model predictions are only as accurate as the mean of the measured data.

\subsection{Model sensitivity analysis}

To better understand how the simulated LUNA output of $V_{\mathrm{c}, \max 25}$ and $J_{\max 25}$ depends on its four parameters and the key model inputs, a one-at-a-time (OAT) sensitivity analysis is performed. In the first analysis, we focus on the model parameters only, and perturb their calibrated values, one at a time, with $\pm 15 \%$. The second sensitivity analysis considers separately the effect of the key environmental variables on the simulated values of $V_{\mathrm{c}, \max 25}$ and $J_{\max 25}$ and perturbs the mean values of the day length (hours), daytime radiation $\left(\mathrm{W} \mathrm{m}^{-2}\right)$, temperature $\left({ }^{\circ} \mathrm{C}\right)$, relative humidity (unitless) and carbon dioxide (ppm) with $\pm 15 \%$.

\subsection{Changes in $V_{c, \max 25}$ and $J_{\max 25}$ under future climate projections}

The global surface temperature could increase as much of $3.9^{\circ} \mathrm{C}$ by the year 2100 relative to present day (Friedlingstein et al., 2014), with large variations across different regions of the globe (Raddatz et al., 2007). Given the dependence of photosynthesis on temperature, it is critical to examine how much future photosynthesis is likely to change in different regions. In this study, we investigate how the LUNA predicted values of $V_{\mathrm{c}, \max 25}$ and $J_{\max 25}$ will change under future climate conditions and how they will affect future estimates of $A_{\text {net }}$, the net photosynthesis rate. The impacts of future climate on $V_{\mathrm{c}, \max 25}, J_{\max 25}$ and $A_{\text {net }}$ are quantified by calculating their values for the leaf layer at the top canopy during the summer season under historic and future climate conditions. Appendix C summarizes the calculation of $A_{\text {net }}$.

We use model outputs from the climate carbon cycle Coupled Model Intercomparison Project Phase 5 (CMIP5) (Meehl et al., 2000) to obtain projections of future climate. Climate modelers have developed four representative concentration pathways (RCPs) for the 21st century (Taylor et al., 2013). Each of them corresponds to a different level of greenhouse gas emission. In this study, we use historic and future climate conditions simulated by the CCSM 4.0 model under scenario RCP8.5, which considers the largest greenhouse gas emissions. We do not consider herein other models and emission scenarios as the main purpose of our study is not to do a complete analysis under all CMIP5 outputs but rather to estimate the potential impact of nitrogen allocation on photosynthesis. Specifically, the 10-year climate record between 1995 and 2004 is used as a benchmark for historic conditions, whereas the climate data between 2090 and 2099 is used for future conditions. We present the LUNA's predicted $V_{\mathrm{c}, \max 25}$ and $J_{\max 25}$ values for the months of the peak growing season. Data from the NOAA Earth System Research Laboratory (Riebeek, 2011) showed that the maximum amount of carbon dioxide drawn from the atmosphere occurs in August and February for the large land masses of the Northern and Southern hemispheres, respectively. As a result, June, July and August are assumed herein to best represent the summer season for the Northern Hemisphere and December, January and February are considered representative for the summer season on the Southern Hemisphere. In this study, $V_{\mathrm{c}, \max 25}$ and $J_{\max 25}$ values are predicted by LUNA using the average values of climate variables for the summer season.

We conduct a third sensitivity analysis to quantify the impacts of future changes in climate variables such as temperature, $\mathrm{CO}_{2}$ concentration, radiation and relative humidity on the simulated values of $V_{\mathrm{c}, \max 25}$ and $J_{\max 25}$. While the first two sensitivity analyses in section 2.6 assume current mean climate conditions, this sensitivity analysis investigates global patterns in sensitivity of $V_{\mathrm{c}, \max 25}$ and $J_{\max 25}$ to future changes in climate variables across different biomes. Specifically, we calculate the percentage difference in the LUNA predicted values of $V_{\mathrm{c}, \max 25}$ and $J_{\max 25}$ using historic and future values of each climate variable. All other climate variables are set at their default (or historic) values.

\section{Results}

\subsection{Model-data comparison of $V_{c, \max 25}$ and $J_{\max 25}$}

The DREAM $(\mathrm{ZS})$ algorithm provides us with the posterior means and standard deviations of the four LUNA parameters (Table 1). The calibrated LUNA model explains $\sim 54 \%$ of the variance in the observed values of $V_{\mathrm{c}, \max 25}$ across all species (Fig. 1a) and $\sim 65 \%$ of the variance in the observed values of $J_{\max 25}$ (Fig. 1b) using the temperature response function TRF1. This response function considers explicitly the thermal acclimation. If TRF2 is used in LUNA, the model is able to explain $\sim 57 \%$ of the variance in the observed values of $V_{\mathrm{c}, \max 25}$ (Fig. 1c) and $\sim 66 \%$ of the variance in the observed values of $J_{\max 25}$ (Fig. 1d) across all species. When the LUNA predictions with TRF1 are compared with the observation data with seasonal cycles, the model explains $\sim 67$ 
Table 1. Mean values and standard deviations (parentheses) of LUNA parameters estimated by using the Differential Evolution Adaptive Metropolis Snooker updater $\left(\mathrm{DREAM}_{(\mathrm{ZS})}\right)$ sampling technique for temperature response functions TRF1 and TRF2. The parameters include (1) $J_{\operatorname{maxb0}}$ (unitless): baseline proportion of nitrogen allocated for electron transport rate, (2) $J_{\text {maxb1 }}$ (unitless): electron transport rate response to light availability, (3) $t_{\mathrm{c}, j 0}$ (unitless): baseline ratio of Rubisco limited rate to light limited rate and (4) $H$ (unitless): electron transport rate response to relative humidity.

\begin{tabular}{lllll}
\hline Statistics & $J_{\operatorname{maxb} 0}$ & $J_{\operatorname{maxb} 1}$ & $t_{\mathrm{c}, j 0}$ & $H$ \\
\hline TRF1 & $0.0311(0.0004)$ & $0.1745(0.0002)$ & $0.8054(0.0015)$ & $6.0999(0.2416)$ \\
\hline TRF2 & $0.0322(0.0002)$ & $0.1695(0.0006)$ & $0.7760(0.0031)$ & $5.7139(0.0354)$ \\
\hline
\end{tabular}
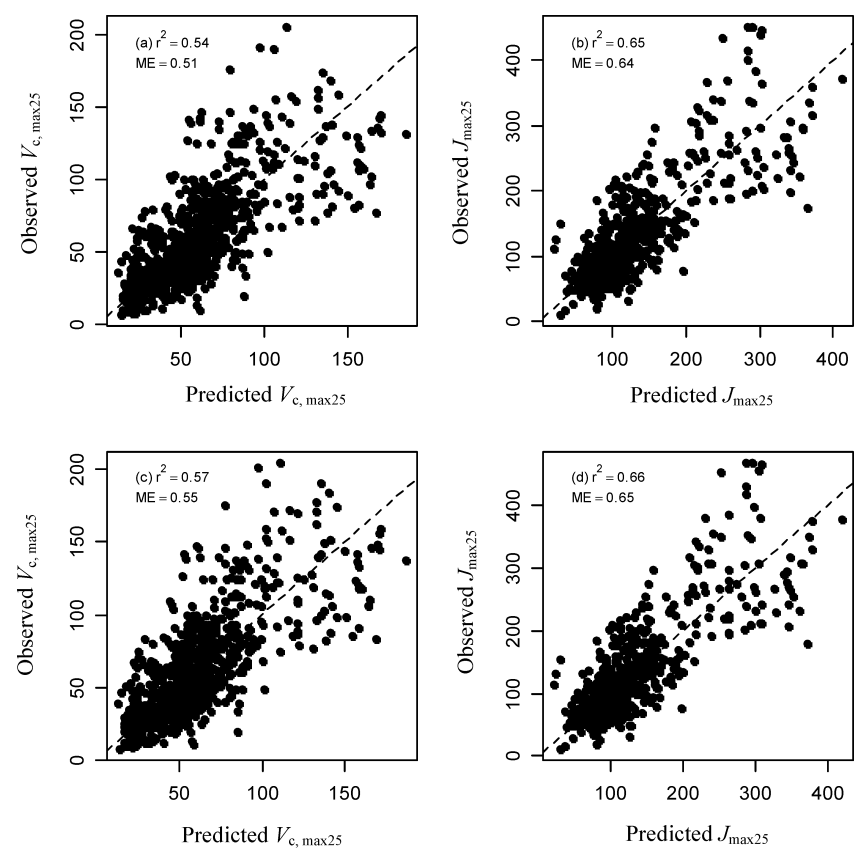

Figure 1. Percentage of variance $\left(r^{2}\right.$ and ME) in observed values of $V_{\mathrm{c}, \max 25}\left(\mu \mathrm{mol} \mathrm{CO} \mathrm{m}^{-2} \mathrm{~s}^{-1}\right)(\mathbf{a}, \mathrm{TRF} 1 ; \mathbf{c}, \mathrm{TRF} 2)$ and $J_{\max 25}\left(\mu \mathrm{mol}\right.$ electron $\left.\mathrm{m}^{-2} \mathrm{~s}^{-1}\right)(\mathbf{b}, \mathrm{TRF} 1 ; \mathbf{d}, \mathrm{TRF} 2)$ explained by the LUNA model for all the species. The $r^{2}$ is derived by a linear regression between observed and modeled values. The dashed line is the $1: 1$ line between observed and modeled values.

and $\sim 53 \%$ of the variance in the observed values of $V_{\mathrm{c}, \max 25}$ and $J_{\max 25}$, respectively (see Fig. S5a, b in the Supplement). The model performs similarly when TRF2 is used (Fig. S5c, d).

Our model also performs well for different PFTs. With TRF1, the LUNA model explains about 57, 58 and $47 \%$ of the variance in the observed values of $V_{\mathrm{c}, \max 25}$ for herbaceous plants (Fig. S6a), shrubs (Fig. S6b) and trees (Fig. S6c), respectively. For $J_{\max 25}$, LUNA explains approximately 49,85 and $46 \%$ of the variances in the observed values of $J_{\max 25}$ for herbaceous plants (Fig. S6d), shrubs (Fig. S6e) and trees (Fig. S6f), respectively. The predictive power of LUNA increases for shrubs when TRF2 is used. About $63 \%$ of the variance in the observed $V_{\mathrm{c}, \max 25}$ values is explained by the model (Fig. S7b), yet a similar performance is observed for herbaceous plants and trees (Fig. S7a, c). The statistics for the predictions of $J_{\max 25}$ are very similar to those reported previously for TRF1 (Fig. S6d-f).

\subsection{Model sensitivity analysis}

Sensitivity analysis shows that all four LUNA model parameters (Table 1) have a positive effect on $V_{\mathrm{c}, \max 25}$ (Fig. 2a, c) and $J_{\max 25}$ (Fig. 2b, d) regardless which temperature response function is used. The parameter $t_{\mathrm{c}, j_{0}}$ has the strongest effect on $V_{\mathrm{c}, \max 25}$ (Fig. 2a, c) while $J_{\operatorname{maxb} 0}$ has the strongest impact on $J_{\max 25}$ (Fig. 2b, d). Parameter $H$ has a much lesser control on the simulated values of both $V_{\mathrm{c}, \max 25}$ and $J_{\max 25}$ (Fig. 2a-d).

Sensitivity analysis of the LUNA model output to its main climate variables shows that radiation most strongly affects the simulated $V_{\mathrm{c}, \max 25}$ values, whereas an increasingly smaller impact is observed for the day length, temperature, $\mathrm{CO}_{2}$ concentration and relative humidity (Fig. 3a, c). The LUNA predicted values of $J_{\max 25}$ appear most sensitive to day length, followed by temperature, radiation, relative humidity and $\mathrm{CO}_{2}$ concentration (Fig. 3b, d). These findings are independent of the TRF being used.

\subsection{Impacts of climate change on $V_{c, \max 25}$ and $J_{\max 25}$}

Across the globe, a similar pattern is observed for TRF1 and TRF2 in the simulated values of $V_{\mathrm{c}, \max 25}$ and $J_{\max 25}$ (Figs. 4 and S8). Under historical climate conditions, the higher latitudes are predicted to have relatively high values of $V_{\mathrm{c}, \max 25}$ and $J_{\max 25}$ while lower latitudes are predicted to have relatively low values of $V_{\mathrm{c}, \max 25}$ and $J_{\max 25}$ (Fig. 4a, c for TRF1; Fig. S8a, c for TRF2). Future climate conditions are likely to decrease significantly the $V_{c, \max 25}$ values for most vegetated lands in large part due to a predicted rise in the temperature and $\mathrm{CO}_{2}$ concentration (Fig. $4 \mathrm{~b}$ for TRF1 and Fig. S8b for TRF2). A somewhat opposite trend is observed for $J_{\max 25}$ with decreasing values at higher latitudes and increasing values at the lower latitudes (Fig. 4d for TRF1 and Fig. S8b for TRF2).

Our results show that the LUNA-simulated $V_{\mathrm{c}, \max 25}$ values are most sensitive to the changes in $\mathrm{CO}_{2}$ concentration, followed by temperature, radiation and relative humid- 

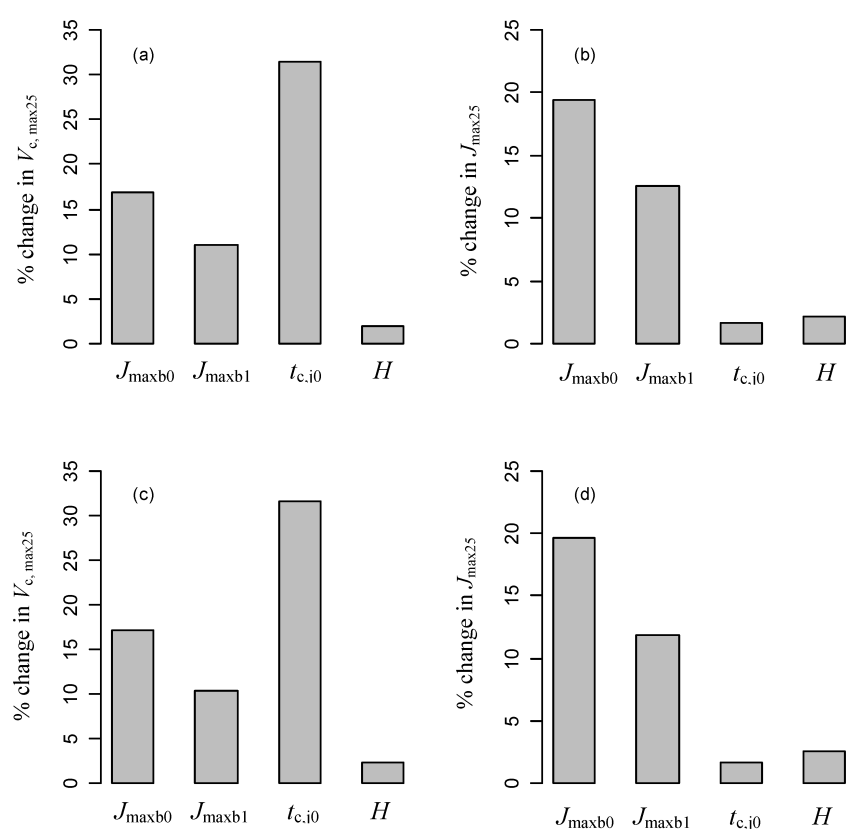

Figure 2. Sensitivities of $V_{\mathrm{c}, \max 25}\left(\mu \mathrm{mol} \mathrm{CO} 2 \mathrm{~m}^{-2} \mathrm{~s}^{-1}\right)$ (a, TRF1; c, TRF2) and $J_{\max 25}\left(\mu \mathrm{mol}\right.$ electron $\left.\mathrm{m}^{-2} \mathrm{~s}^{-1}\right)(\mathbf{b}, \mathrm{TRF} 1 ; \mathbf{d}, \mathrm{TRF} 2)$ to changes in model parameters. Each parameter $\left(J_{\operatorname{maxb} 0}, J_{\operatorname{maxb} 1}\right.$, $t_{\mathrm{c}, j 0}$, and $H$ ) is varied one at a time by $\pm 15 \%$ of its fitted value. The values of environmental variables are held fixed at their mean values with day length $=14 \mathrm{~h}$, daytime radiation $=182 \mathrm{~W} \mathrm{~m}^{-2}$, temperature $=14^{\circ} \mathrm{C}$, relative humidity $=0.6$ (unitless) and $\mathrm{CO}_{2}$ concentration $=393 \mathrm{ppm}$. $V_{\mathrm{c}, \max 25}$ and $J_{\max 25}$ values are first obtained at changed parameter values and the percentage changes in $V_{\mathrm{c}, \max 25}$ and $J_{\max 25}$ are then calculated relative to the baseline values of $V_{\mathrm{c}, \max 25}$ and $J_{\max 25}$ predicted based the default parameter values. Positive values indicate that the increase in a specific model parameter leads to larger values of $V_{\mathrm{c}, \max 25}$ or $J_{\max 25}$, while negative values indicate that the increase in a specific model parameter leads to smaller values of $V_{\mathrm{c}, \max 25}$ or $J_{\max 25}$.

ity (Fig. 5a-d for TRF1 and Fig. S9a-d for TRF2). The variable $J_{\max 25}$ appears most sensitive to the changes in temperature, and then radiation, relative humidity and $\mathrm{CO}_{2}$ (Fig. 6a-d for TRF1 and Fig. S10a-d for TRF2). Across the globe, temperature has negative impacts on $V_{\mathrm{c}, \max 25}$ when using TRF1 (Fig. 5a); however, when TRF2 is used, $V_{c, \max 25}$ is found to increase at the lower latitudes (Fig. S9a).

The simulations of LUNA demonstrate that the future summer-season mean photosynthetic rate at the top leaf layer might be substantially overestimated if acclimation of $V_{\mathrm{c}, \max 25}$ and $J_{\max 25}$ under future climate conditions (i.e., using historic values of $V_{\mathrm{c}, \max 25}$ and $J_{\max 25}$ ) is not explicitly considered (Fig. 7a, b). This is especially true for regions with high temperatures (Fig. S11). Future estimates of the summer-season mean photosynthesis rate are much higher under TRF1 than TRF2 (Fig. 7b). The omission of acclimation could lead to a 10.1 and $16.3 \%$ overestimation in the
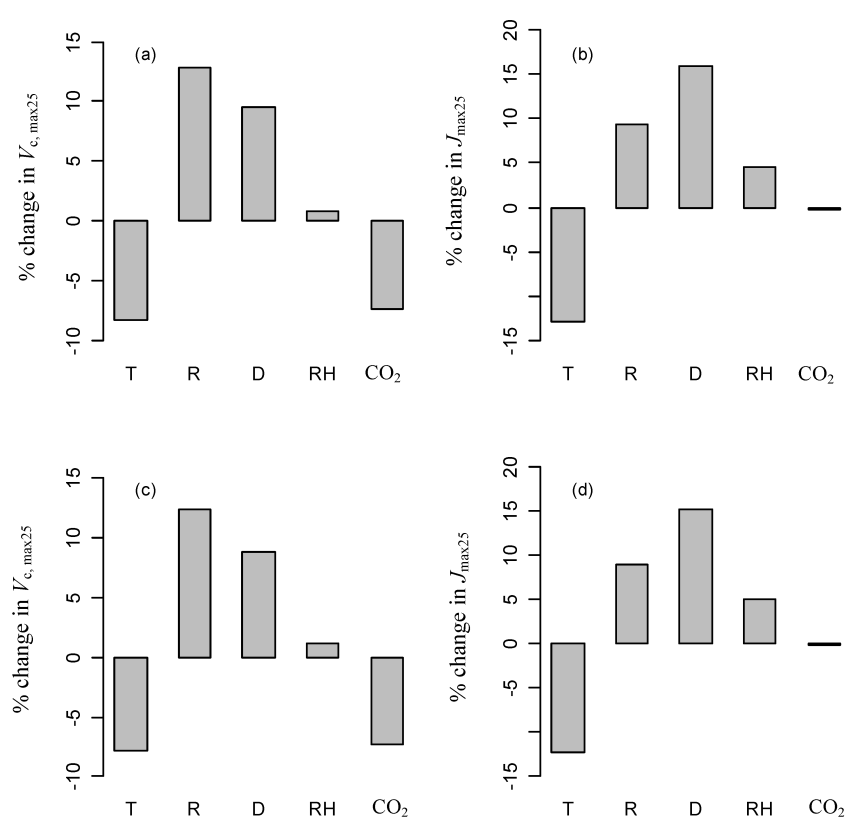

Figure 3. Sensitivities of $V_{\mathrm{c}, \max 25}\left(\mu \mathrm{mol} \mathrm{CO} 2 \mathrm{~m}^{-2} \mathrm{~s}^{-1}\right)(\mathbf{a}: \mathrm{TRF} 1$, c: TRF2) and $J_{\max 25}\left(\mu \mathrm{mol}\right.$ electron $\left.\mathrm{m}^{-2} \mathrm{~s}^{-1}\right)(\mathbf{b}$ : TRF1, d: TRF2) to changes in environmental variables including day length $(D)$, daytime radiation $(R)$, temperature $(T)$, relative humidity $(\mathrm{RH})$ and $\mathrm{CO}_{2}$ concentration. Each environmental variable is varied one at a time by $\pm 15 \%$ around their mean values with day length $=14 \mathrm{~h}$, daytime radiation $=182 \mathrm{~W} \mathrm{~m}^{-2}$, temperature $=14^{\circ} \mathrm{C}$, relative humidity $=0.6$ (unitless) and $\mathrm{CO}_{2}$ concentration $=393 \mathrm{ppm}$. The model parameters $\left(J_{\operatorname{maxb} 0}, J_{\operatorname{maxb} 1}, t_{\mathrm{c}, j 0}\right.$, and $\left.H\right)$ are held fixed at their fitted values. $V_{\mathrm{c}, \max 25}$ and $J_{\max 25}$ values are first obtained at changed environmental conditions and percentage changes in $V_{\mathrm{c}, \max 25}$ and $J_{\max 25}$ are calculated relative to the baseline values of $V_{\mathrm{c}, \max 25}$ and $J_{\max 25}$ under the mean climate conditions in the data. Positive values indicate that the increase in a specific environmental variable leads to larger values of $V_{\mathrm{c}, \max 25}$ and $J_{\max 25 \text {, while }}$ negative values indicate that the increase in a specific environmental variable leads to smaller values of $V_{\mathrm{c}, \max 25}$ and $J_{\max 25}$.

global net photosynthetic rate at the top canopy layer for TRF1 and TRF2, respectively.

\section{Discussion}

\subsection{Model limitations}

The LUNA model built on the assumption that nitrogen is allocated according to optimality principles explains a large part of the global-scale variability observed in $V_{\mathrm{c}, \max 25}$ $(\sim 55 \%)$ and $J_{\max 25}(\sim 65 \%)$, regardless which TRF is used. This approach used by LUNA also mimics accurately seasonal cycles and PFT-specific values of $V_{\mathrm{c}, \max 25}$ and $J_{\max 25}$ (Figs. S5-S7), and has a much better overall predictive power than a multiple linear regression with $\mathrm{LNC}_{\mathrm{a}}$ and LMA as main predictors. Such a linear model is able to explain only, 

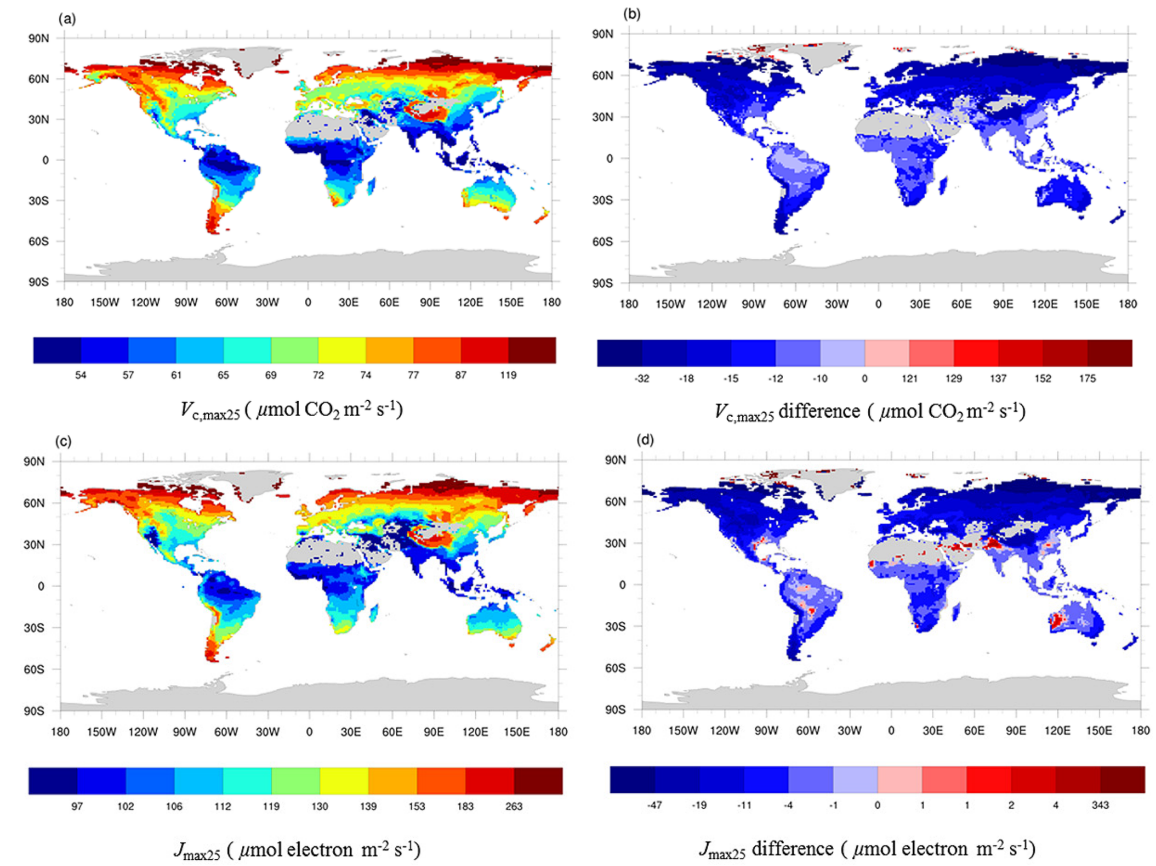

Figure 4. Summer-season photosynthetic capacity for the top leaf layer in the canopy under historical climatic conditions (a: $V_{\mathrm{c}, \text { max } 25}$ $\left(\mu \mathrm{mol} \mathrm{CO} 2 \mathrm{~m}^{-2} \mathrm{~s}^{-1}\right), \mathbf{b}: J_{\max 25}\left(\mu \mathrm{mol}\right.$ electron $\left.\mathrm{m}^{-2} \mathrm{~s}^{-1}\right)$ ) and the difference in either $V_{\mathrm{c}, \max 25}$ (b) or $J_{\max 25}$ (d) due to changed climatic conditions in the future. The difference is calculated by subtracting the photosynthetic capacity predicted by the LUNA model under the historical climate conditions from that under the future climate conditions. The historical climate is represented by the 10 -year monthly averages over years 1995-2004 and the future climate is represented by the 10-year monthly averages over years 2090-2099. The model is run by using TRF1, which is a temperature response function that considered the thermal acclimation.
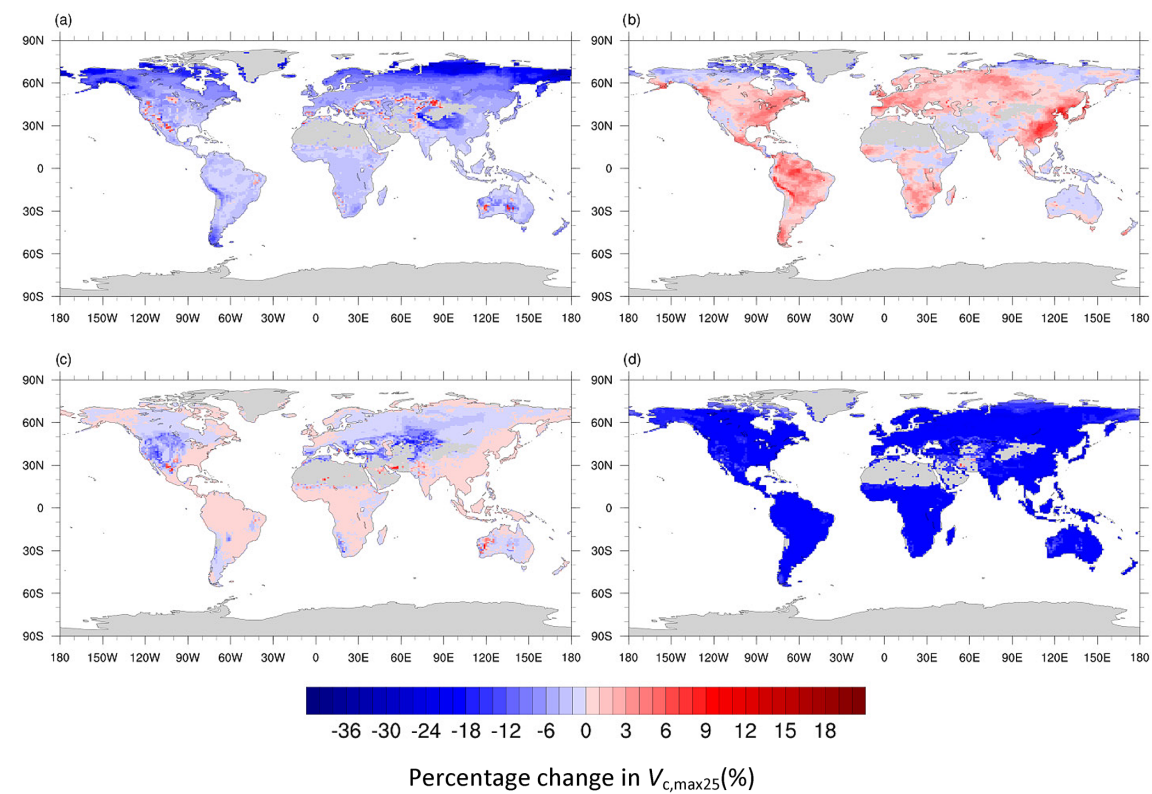

Figure 5. Sensitivity of $V_{\mathrm{c}, \max 25}\left(\mu \mathrm{mol} \mathrm{CO} \mathrm{m}^{-2} \mathrm{~s}^{-1}\right)$ to projected future changes in environmental variables including temperature (a), radiation (b), humidity (c) and $\mathrm{CO}_{2}$ (d) at the global scale for TRF1. The sensitivity analysis is conducted by changing the value of an individual environmental variable from its 10-year monthly averages in the past (1995-2004) to those in the future (2090-2099) for each individual grid cell across the globe. Positive values indicate that the increase in a specific environmental variable leads to larger values of $V_{\mathrm{c}, \max 25}$, while negative values indicate that the increase in a specific environmental variable leads to smaller values of $V_{\mathrm{c}, \text { max } 25}$. 

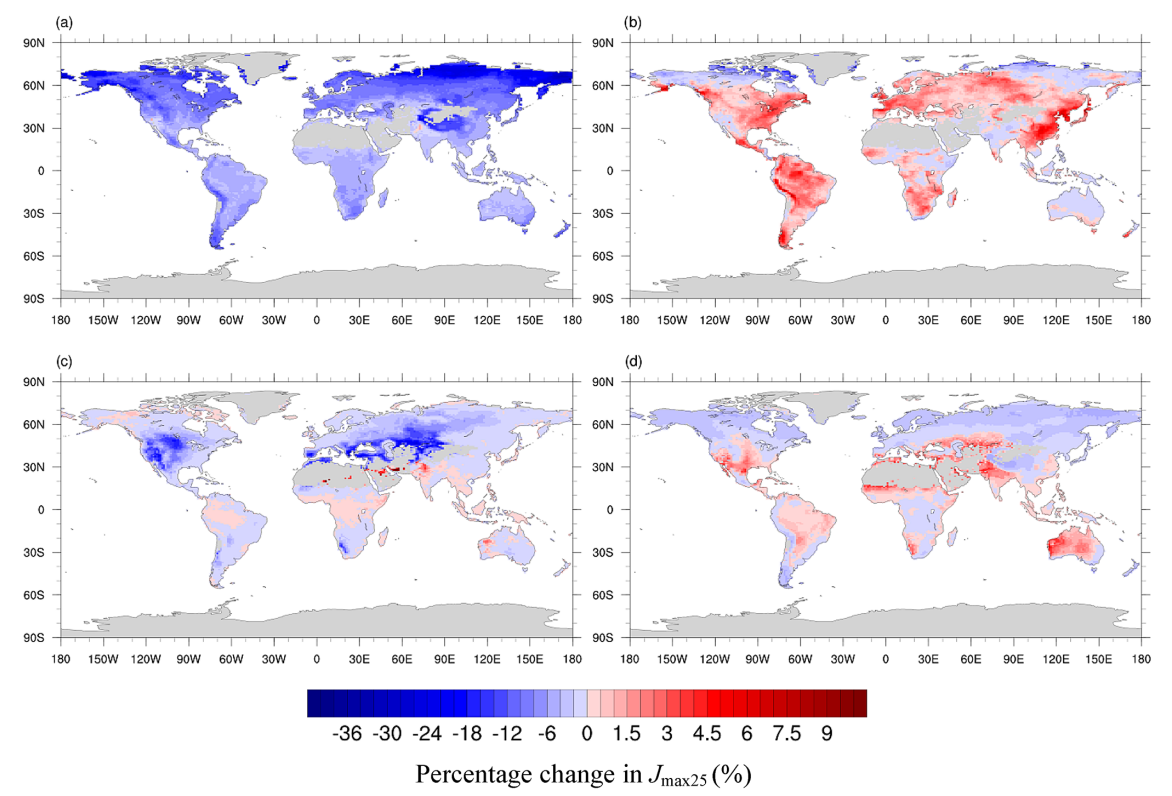

Figure 6. Sensitivity of $J_{\max 25}\left(\mu \mathrm{mol}\right.$ electron $\mathrm{m}^{-2} \mathrm{~s}^{-1}$ ) to projected future changes in environmental variables including temperature (a), radiation (b), humidity (c) and $\mathrm{CO}_{2}$ (d) at the global scale using TRF1. The sensitivity analysis is conducted by changing the value of an individual environmental variable from its 10-year monthly averages in the past (1995-2004) to those in the future (2090-2099) for each individual grid cell across the globe. Positive values indicate that the increase in a specific environmental variable leads to larger values of $J_{\max 25}$, while negative values indicate that the increase in a specific environmental variable leads to smaller values of $J_{\max 25}$.

for both TRFs, about $22 \%$ of the variance in the observed $V_{\mathrm{c}, \max 25}$ values (Fig. S12a, d) and approximately $13 \%$ of the variance in the observed $J_{\max 25}$ values (Fig. S12b, d). These results suggest that our model includes many of the key variables that determine the spatial and temporal variation of $V_{\mathrm{c}, \max 25}$ and $J_{\max 25}$ across the globe. The remaining portion of the variance that cannot be explained by the LUNA model can be related to variability within the 125 species considered in this study. There are inherent intraspecific variations in leaf traits (Valladares et al., 2000) and in photosynthetic capacity (Moran et al., 2016). Data availability limits the number of species that can be considered in the present analysis and favors a single LUNA calibration for all species. Indeed, the data for individual species normally did not cover a sufficiently large range of environmental conditions. When more data become available for individual species in the future, we can revisit the calibration procedure and fit our model to specific PFTs pending a sufficiently large enough coverage of environmental conditions. We posit that such a model will be able to adequately capture a larger portion of the variability observed in $V_{\mathrm{c}, \max 25}$ and $J_{\max 25}$.

Other deficiencies of LUNA might be related to unexplored nutrient limitations and other plant physiological properties. For example, low phosphorus concentrations can reduce considerably the nitrogen use efficiency of tropical plants with typically modest to low nitrogen (Cernusak et al., 2010; Reich and Oleksyn, 2004), suggesting that our LUNA model can be enhanced by considering multiple dif- ferent nutrient limitations simultaneously (Goll et al., 2012; Walker et al., 2014; Wang et al., 2010). Our treatment of the photosynthetic capacity can also be improved by incorporating a species-specific mesophyll and stomatal conductance (Medlyn et al., 2011), by analyzing properties such as leaf life span (Wright et al., 2004), and by considering soil $\mathrm{pH}$, nutrient availability and water availability (Maire et al., 2015). Unexplored nutrient limitations and other plant physiological properties could also play a factor in the limitation of our model. For example, the nitrogen use efficiency of tropical plants (typically modest to low nitrogen) can be diminished by low phosphorus (Cernusak et al., 2010; Reich and Oleksyn, 2004), suggesting that our model could be improved by considering multiple nutrient limitations (Goll et al., 2012; Walker et al., 2014; Wang et al., 2010). Our treatment of photosynthetic capacity could also be improved by incorporating species-specific mesophyll and stomatal conductance (Medlyn et al., 2011), by analyzing leaf properties such as leaf life span (Wright et al., 2004), or by considering soil nutrient, soil water availability and soil $\mathrm{pH}$ (Maire et al., 2015).

Measurement errors of $V_{\mathrm{c}, \max 25}$ and $J_{\max 25}$ also affect negatively the ability of LUNA to describe perfectly the observational data. These errors can originate from many different sources but are rarely quantified in the literature. They can play a significant role in parameter fitting. Indeed, previous research has shown that the value of $C_{i}$ in the Farquhar et al. (1980) model used to differentiate between Rubisco and 
(a)
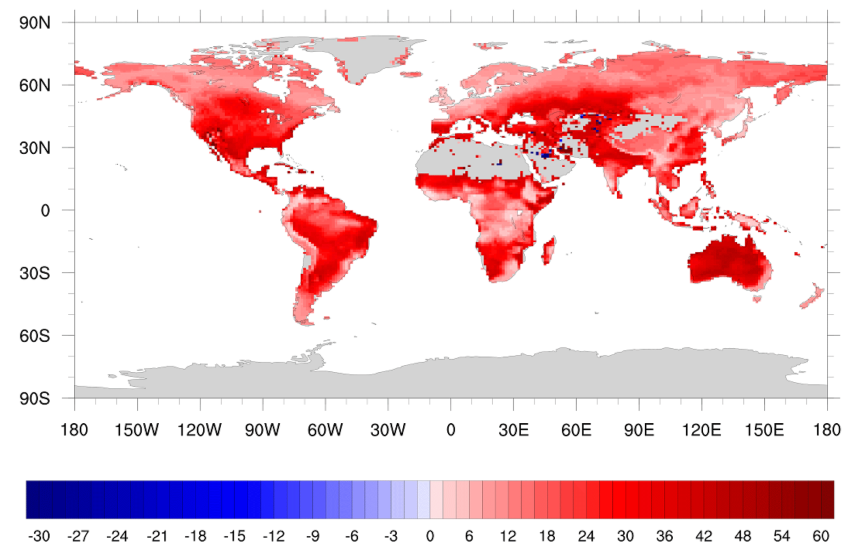
Percentage change in $A_{\text {net }}(\%)$

(b)
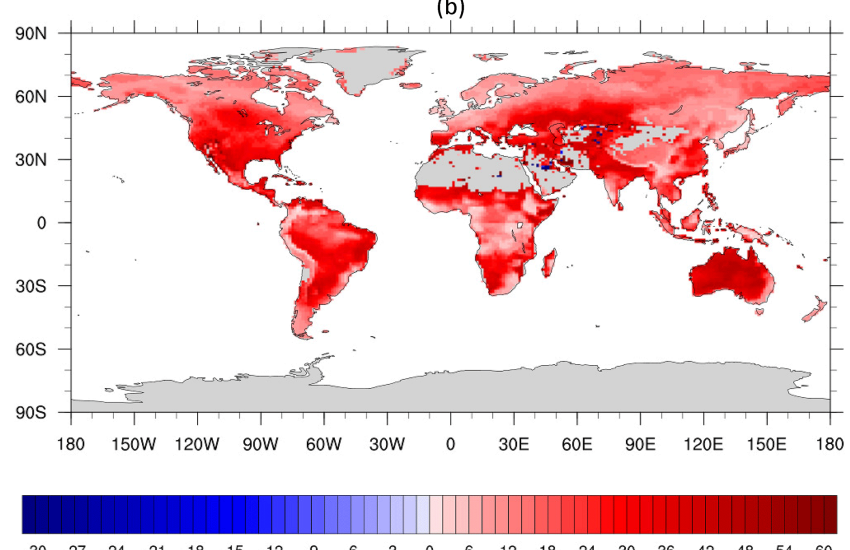

Percentage change in $A_{\text {net }}(\%)$

Figure 7. Percentage differences in estimated net photosynthetic rate for the leaf layer at the top of the canopy $\left(A_{\text {net }}\right.$, $\mu \mathrm{mol} \mathrm{CO} 2 \mathrm{~m}^{-2} \mathrm{~s}^{-1}$ ) under future climate conditions (a: TRF1, b: TRF2) by using LUNA predicted values of $V_{\mathrm{c}, \max 25}(\mu \mathrm{mol}$ $\left.\mathrm{CO}_{2} \mathrm{~m}^{-2} \mathrm{~s}^{-1}\right)$ and $J_{\max 25}\left(\mu \mathrm{mol}\right.$ electron $\left.\mathrm{m}^{-2} \mathrm{~s}^{-1}\right)$ under historic versus future climate conditions. Positive values indicate overestimation by using fixed (or historic) $V_{\mathrm{c}, \max 25}$ and $J_{\max 25}$ while negative values indicate underestimation. The historic climate is represented by the 10-year monthly averages over years 1995-2004 and the future climate is represented by the 10 -year monthly averages over years 2090-2099.

Ribulose-1,5-bisphosphate (RuBP) limitations, could be estimated from different methods in the literature (Miao et al., 2009). Furthermore, it is particularly difficult to obtain accurate and biologically realistic estimates of dark respiration (but see Dubois et al., 2007), and consequently, dark respiration is sometimes not reported (Medlyn et al., 2002b).

\subsection{Importance of environmental control on $V_{c, \max 25}$ and $J_{\max 25}$}

Our model predicts that higher temperatures generally lead to lower values of $V_{\mathrm{c}, \max 25}$ and $J_{\max 25}$ (Fig. $3 \mathrm{a}, \mathrm{c}$ ). As temperature increases, the nitrogen use efficiencies of $V_{\mathrm{c}, \max }$ and $J_{\max }$ also increase and thus plants need a lower amount of nitrogen allocated for carboxylation and electron transport. This is true for all the sites except for $V_{\mathrm{c}, \max 25}$ in the warmest regions of our planet when TRF2 is used (Fig. S9a). This is explained by a large increase in the nighttime temperature of LUNA (e.g., 22 to $30^{\circ} \mathrm{C}$ ) as the daytime temperature (e.g., from 31 to $33^{\circ} \mathrm{C}$ ) is constrained by the maximum temperature for optimization in TRF2 (i.e., $33^{\circ} \mathrm{C}$ ). To maximize the net photosynthetic carbon gain, the model predicts a higher proportion of nitrogen allocated to carboxylation to compensate for a higher nighttime respiration rate. Therefore, the LUNA model predicts higher values of $V_{\mathrm{c}, \max 25}$. Yet, this may result from a deficiency of TRF2 in that this response function does not allow for thermal acclimation under global warming (Lombardozzi et al., 2015).

Our model predicts that the future changes in atmospheric $\mathrm{CO}_{2}$ concentration has a negligible effect on $J_{\max 25}$, a finding that is in agreement with results from other studies (e.g., Maroco et al., 2002). A meta-analysis of 12 Free-Air Carbon dioxide Enrichment (FACE) experiments demonstrated reductions in $J_{\max }$ on the order of $5 \%$ but with a $10 \%$ reduction in $V_{\mathrm{c}, \max 25}$ under elevated $\mathrm{CO}_{2}$ concentrations (Long et al., 2004). Our model also predicts that the relative humidity has a relatively minor effect on $V_{\mathrm{c}, \max 25}$. This may be due to the fact that most of the values of $V_{\mathrm{c}, \max 25}$ and $J_{\max 25}$ in our data set coincide with relatively high values of the humidity. As LUNA does not consider the effects of drought on photosynthesis, it may have underestimated the effects of water scarcity on $V_{\mathrm{c}, \max 25}$ under low humidity conditions $(\mathrm{Xu}$ and Baldocchi, 2003). Under prolonged drought, plants close their stomata and photosynthesis is greatly reduced (Breshears et al., 2008; McDowell, 2011). Without sufficient carbon input, photosynthetic enzymes may degenerate during the high temperatures of a drought, which could decrease $V_{\text {c,max25 }}$ substantially (Limousin et al., 2010; $\mathrm{Xu}$ and Baldocchi, 2003).

There are many different ways to incorporate environmental controls on $V_{\mathrm{c}, \max 25}$ and $J_{\max 25}$. One such approach is to use relatively simple empirical relationships between environmental variables and $V_{\mathrm{c}, \max 25}$ and $J_{\max 25}$ (e.g., Ali et al., 2015; Verheijen et al., 2013). Such functions can improve the model performance (Verheijen et al., 2015), yet may exhibit rather poor extrapolative capabilities under future climate conditions. The optimality hypothesis used by LUNA is arguably better rooted in ecologic theory, and is therefore expected to exhibit a better predictive quality when confronted with novel future climate conditions. Indeed, the concept of optimality has been applied to the prediction of many different plant functions and structures under a wide array of 
environmental conditions. Examples include carbon allocation (Franklin et al., 2012), leaf C: N (Thomas and Williams, 2014), root distribution (McMurtrie et al., 2012) and stomatal conductance (Cowan and Farquhar, 1977). For photosynthetic capacity optimization, Haxeltine and Prentice (1996) have predicted $V_{\mathrm{c}, \max 25}$ based on a trade-off analysis of photosynthesis and respiration. This concept has been incorporated in different land surface models such as LPJ-GUESS (Smith et al., 2001) and LPJmL (Sitch et al., 2003). Both LUNA and the model of Haxeltine and Prentice (1996), hereafter conveniently referred to as HP, consider $V_{\mathrm{c}, \max 25}$ and respiration. The LUNA model is currently limited to prediction at the leaf level only while the HP model is applicable for both the leaf and canopy level. Nevertheless, key improvements of LUNA over HP include an explicit consideration of light capture, electron transport and storage. Furthermore, the parameters of LUNA have been derived from a much larger global data set, with many different environmental conditions.

\subsection{Importance of changes in $V_{c, \max 25}$ and $J_{\max 25}$ to future photosynthesis estimation}

Our model suggests that most regions of the world will likely experience reductions in $V_{\mathrm{c}, \max 25}$ (Figs. $4 \mathrm{~b}$ and $\mathrm{S} 8 \mathrm{~b}$ ) due to global warming. An increase of the temperature (Fig. S13) and atmospheric $\mathrm{CO}_{2}$ concentration is expected to increase the nitrogen use efficiency of Rubisco and thus plants are able to reduce the amount of nitrogen allocated for Rubisco to reduce the carbon cost required for enzyme maintenance. Similarly, $J_{\max 25}$ will also decrease globally, except in regions where the present temperatures of the growing season are relatively high (Fig. S12b). The increase of $J_{\max 25}$ can be attributed to leaf temperature limitations and increased shortwave radiation (Figs. S14 and S15). Temperature will have a relatively small impact on nitrogen allocation in regions with historically high temperatures during the growing season because leaf temperature is already close to or higher than the upper limit of optimal nitrogen allocation $\left(42^{\circ} \mathrm{C}\right.$ for TRF1 and $33{ }^{\circ} \mathrm{C}$ for TRF2). Based on Eq. (A11), higher levels of shortwave solar radiation will increase nitrogen allocation to electron transport (Evans and Poorter, 2001).
If we do not account for the potential acclimation of $V_{\text {c, } \max 25}$ and $J_{\max 25}$ under future climate conditions, our analysis based on the LUNA model indicates that ESM predictions of future global photosynthesis at the uppermost leaf layer will likely be overestimated by as much as $10-16 \%$ if $V_{\mathrm{c}, \max 25}$ and $J_{\max 25}$ are held fixed (Fig. 7). This overestimation is larger for TRF2 (16.3\%) than TRF1 (10.1\%) and can result from the fact that TFR2 does not account for thermal acclimation under future climate conditions. Consequently, LUNA predicts a large nitrogen allocation acclimation under climate change. In both cases, our results suggest that, to reliably predict global plant responses to future climate change, ESMs should take into explicit consideration environmental controls on $V_{\mathrm{c}, \max 25}$ and $J_{\max 25}$. It has been suggested recently that nitrogen-related factors are not well represented in ESMs (Houlton et al., 2015; Wieder et al., 2015). Our nitrogen partitioning scheme would help remove the prediction bias of future photosynthetic rates, which will also improve considerably related climate processes that are dependent on these predictions (Bonan et al., 2011; Knorr and Kattge, 2005; Rogers, 2014).

\section{Code availability}

The LUNA model has been implemented in CLM5.0 and will be made publicly available with its release in 2016. Standalone codes of LUNA are available in MATLAB, FORTRAN and $\mathrm{C}$. These source codes can be obtained from the corresponding author upon request. 


\section{Appendix A: Leaf utilization of nitrogen for assimilation (LUNA) model}

The LUNA model considers nitrogen allocation within a given leaf layer in the canopy that has a predefined leafarea-based plant leaf nitrogen content availability $\left(\mathrm{LNC}_{\mathrm{a}}\right.$; $\mathrm{g} \mathrm{N} \mathrm{m}^{-2}$ leaf) to support its growth and maintenance. The structure of the LUNA model is adapted from $\mathrm{Xu}$ et al. (2012), where the plant nitrogen at the leaf level is divided into four pools: structural nitrogen $\left(N_{\mathrm{str}} ; \mathrm{g} \mathrm{N} \mathrm{m}^{-2}\right.$ leaf $)$, photosynthetic nitrogen $\left(N_{\mathrm{psn}} ; \mathrm{g} \mathrm{N} \mathrm{m}^{-2}\right.$ leaf), storage nitrogen $\left(N_{\text {store }} ; \mathrm{g} \mathrm{N} \mathrm{m}^{-2}\right.$ leaf $)$ and respiratory nitrogen $\left(N_{\text {resp }}\right.$; $\mathrm{g} \mathrm{N} \mathrm{m}^{-2}$ leaf). Namely,

$\mathrm{LNC}_{\mathrm{a}}=N_{\text {psn }}+N_{\text {str }}+N_{\text {store }}+N_{\text {resp }}$.

The photosynthetic nitrogen, $N_{\mathrm{psn}}$, is further divided into nitrogen for light capture $\left(N_{\mathrm{lc}} ; \mathrm{g} \mathrm{N} \mathrm{m}^{-2}\right.$ leaf), nitrogen for electron transport $\left(N_{\mathrm{et}} ; \mathrm{g} \mathrm{N} \mathrm{m}^{-2}\right.$ leaf) and nitrogen for carboxylation $\left(N_{\mathrm{cb}} ; \mathrm{g} \mathrm{N} \mathrm{m}^{-2}\right.$ leaf). Namely,

$N_{\mathrm{psn}}=N_{\mathrm{et}}+N_{\mathrm{cb}}+N_{\mathrm{lc}}$.

The structural nitrogen, $N_{\text {str }}$, is calculated as the multiplication of leaf mass per unit area (LMA; $g$ biomass $\mathrm{m}^{-2}$ leaf), and the structural nitrogen content (SNC; $\mathrm{g} \mathrm{N} \mathrm{g}^{-1}$ biomass). Namely,

$N_{\mathrm{str}}=\mathrm{SNC} \cdot \mathrm{LMA}$,

where SNC is set to be fixed at $0.002\left(\mathrm{~g} \mathrm{~N} \mathrm{~g}^{-1}\right.$ biomass), based on data on $\mathrm{C}: \mathrm{N}$ ratio from dead wood (White et al., 2000). The functional leaf nitrogen content $\left(\mathrm{FNC}_{\mathrm{a}}\right.$; $\mathrm{g} \mathrm{N} \mathrm{m}^{-2}$ leaf) is defined by subtracting structural nitrogen content, $N_{\text {str }}$, from the total leaf nitrogen content $\left(\mathrm{LNC}_{\mathrm{a}}\right.$; $\mathrm{g} \mathrm{N} \mathrm{m}^{-2}$ leaf),

$\mathrm{FNC}_{\mathrm{a}}=\mathrm{LNC}_{\mathrm{a}}-N_{\mathrm{str}}$.

We assume that plants optimize their nitrogen allocations (i.e., $N_{\text {store }}, N_{\text {resp }}, N_{\text {lc }}, N_{\text {et }}, N_{\text {cb }}$ ) to maximize the net photosynthetic carbon gain, defined as the gross photosynthesis (A) minus the maintenance respiration for photosynthetic enzymes $\left(R_{\mathrm{psn}}\right)$, under specific environmental conditions and given plant's strategy of leaf nitrogen use. Namely, the solutions of nitrogen allocations $\left\{N_{\text {store }}, N_{\text {resp }}, N_{\mathrm{lc}}, N_{\mathrm{et}}, N_{\mathrm{cb}}\right\}$ can be estimated as follows,

$$
\begin{gathered}
\left\{\hat{N}_{\text {store, }}, \hat{N}_{\text {resp }}, \hat{N}_{\text {lc }}, \hat{N}_{\text {ett }}, \hat{N}_{\text {cb }}\right\}= \\
N_{\text {store }}+N_{\text {resp }}+N_{\text {lc }}+N_{\text {et }}+N_{\text {cb }}<\text { FNC }_{\mathrm{a}}
\end{gathered}\left(A-R_{\text {psn }}\right) .
$$

The gross photosynthesis, $A$, is calculated with a coupled leaf gas exchange model based on the Farquhar et al. (1980) model of photosynthesis and Ball-Berry-type stomatal conductance model (Ball et al., 1987) (See Appendix C for details). The maintenance respiration for photosynthetic enzymes, $R_{\mathrm{psn}}$, is calculated by the multiplication of total photosynthetic nitrogen $\left(\mathrm{N}_{\mathrm{psn}}\right)$ and the maintenance respiration cost for photosynthetic enzyme (NUE $\mathrm{rp}_{\mathrm{rp}}$, see Appendix D), namely,

$R_{\mathrm{psn}}=\mathrm{NUE}_{\mathrm{rp}} N_{\mathrm{psn}}$.

In the LUNA model, the maximum electron transport rate $\left(J_{\max } ; \mu\right.$ mol electron $\left.\mathrm{m}^{-2} \mathrm{~s}^{-1}\right)$ is simulated to have a baseline allocation of nitrogen and additional nitrogen allocation to change depending on the average daytime photosynthetic active radiation (PAR; $\mu$ mol electron $\mathrm{m}^{-2} \mathrm{~s}^{-1}$ ), day length (hours) and air humidity. Specifically, we have

$J_{\max }=J_{\max 0}+J_{\operatorname{maxb} 1} f$ (day length) $f$ (humidity) $\alpha$ PAR.

The baseline electron transport rate, $J_{\max 0}$ $\left(\mu \mathrm{mol}\right.$ electron $\left.\mathrm{m}^{-2} \mathrm{~s}^{-1}\right)$, is calculated as follows,

$J_{\max 0}=J_{\operatorname{maxb} 0} \mathrm{FNC}_{\mathrm{a}} \mathrm{NUE}_{J_{\max }}$,

where $J_{\operatorname{maxb0}}$ (unitless) is the baseline proportion of nitrogen allocated for electron transport rate. $\mathrm{NUE}_{J_{\max }}$ $\left(\mu \mathrm{mol}\right.$ electron $\left.\mathrm{s}^{-1} \mathrm{~g}^{-1} \mathrm{~N}\right)$ is the nitrogen use efficiency of $J_{\max }$ (see Eq. D2 for details). $J_{\operatorname{maxb} 1}$ (unitless) is a coefficient determining the response of the electron transport rate to amount of absorbed light (i.e. $\alpha$ PAR). $f$ (day length) is a function specifies the impact of day length (hours) on $J_{\max }$ in view that longer day length has been demonstrated by previous studies to alter $V_{\mathrm{c}, \max 25}$ and $J_{\max 25}$ (Bauerle et al., 2012; Comstock and Ehleringer, 1986) through photoperiod sensing and regulation (e.g., Song et al., 2013). Following Bauerle et al. (2012), $f$ (day length) is simulated as follows,

$f($ day length $)=\left(\frac{\text { day length }}{12}\right)^{2}$,

where $f$ (humidity) represents the impact of air humidity on $J_{\max }$. We assume that higher humidity leads to higher $J_{\max }$ with less water limitation on stomata opening and that low relative humidity has a stronger impact on nitrogen allocation due to greater water limitation. When relative humidity (RH; unitless) is too low, we assume that plants are physiologically unable to reallocate nitrogen. We therefore assume that there exists a critical value of relative humidity $\left(\mathrm{RH}_{0}=0.25\right.$; unitless), below which there is no optimal nitrogen allocation. Based on the above assumptions, we have

$f$ (humidity) $=\left(1-e^{\left(-H \frac{\max \left(\mathrm{RH}_{-} \mathrm{RH}_{0}, 0\right)}{1-\mathrm{RH}_{0}}\right)}\right)$,

where $H$ (unitless) specifies the impact of relative humidity on electron transport rate. Replacing Eq. (A7) with Eqs. (A8), (A9) and (A10), we have

$$
\begin{aligned}
J_{\max }= & J_{\operatorname{maxb} 0} \mathrm{FNC}_{\mathrm{a}} \mathrm{NUE}_{J_{\max }} \\
& +J_{\operatorname{maxb} 1}\left(\frac{\text { day length }}{12}\right)^{2} \\
& \left(1-\mathrm{e}^{\left(-H^{\left.\frac{\max \left(\mathrm{RH}_{\mathrm{RH}}, 0\right)}{1-\mathrm{RH}_{0}}\right)}\right) \alpha \text { PAR. }}\right.
\end{aligned}
$$

The efficiency of light energy absorption (unitless), $\alpha$, is calculated depending on the amount of nitrogen allocated for 
light capture, $N_{\mathrm{lc}}$. Following Niinemets and Tenhunen (1997) we have,

$\alpha=\frac{0.292}{1+\frac{0.076}{N_{\mathrm{lc}} C_{\mathrm{b}}}}$,

where 0.292 is the conversion factor from photon to electron. $C_{\mathrm{b}}$ is the conversion factor (1.78) from nitrogen to chlorophyll. After we estimate $J_{\max }$, the actual electron transport rate with the daily maximum radiation $\left(J_{x}\right)$ can be calculated using the empirical expression of Smith (1937),

$J_{x}=\frac{\alpha \mathrm{PAR}_{\max }}{\left(1+\frac{\alpha^{2} \mathrm{PAR}_{\max }^{2}}{J_{\max }^{2}}\right)^{0.5}}$,

where PAR $_{\max }\left(\mu \mathrm{mol} \mathrm{m}{ }^{-2} \mathrm{~s}^{-1}\right.$ ) is the maximum photosynthetically active radiation during the day.

Based on Farquhar et al. (1980) and Wullschleger (1993), we calculate the electron-limited photosynthetic rate under daily maximum radiation $\left(W_{J_{x}}\right)$ and the Rubisco-limited photosynthetic rate $\left(W_{\mathrm{c}}\right)$ as follows,

$W_{J_{x}}=K_{j} J_{x}$,

$W_{\mathrm{c}}=K_{\mathrm{c}} V_{\mathrm{c}, \max }$,

where $K_{j}$ and $K_{\mathrm{c}}$ are the conversion factors from $V_{\mathrm{c} \text {, max }}$ to $W_{\mathrm{c}}$ and from $J_{x}$ to $\mathrm{W}_{J_{x}}$, respectively (see Eqs. C4 and C6 in Appendix $\mathrm{C}$ for details of calculation). Based on $\mathrm{Xu}$ et al. (2012), Maire et al. (2012) and Walker et al. (2014), we assume that $W_{\mathrm{c}}$ is proportional to $W_{J_{x}}$. Specifically, we have

$W_{\mathrm{c}}=t_{\mathrm{c}, j} W_{J_{x}}$,

where $t_{\mathrm{c}, j}$ is the ratio of $W_{\mathrm{c}}$ to $W_{J_{x}}$. We recognize that this ratio may change depending on the nitrogen use efficiency of carboxylation and electron transport (Ainsworth and Rogers, 2007) and therefore introduce the modification as follows,

$t_{\mathrm{c}, j}=t_{\mathrm{c}, j_{0}}\left(\frac{\mathrm{NUE}_{\mathrm{c}} / \mathrm{NUE}_{\mathrm{j}}}{\mathrm{NUE}_{\mathrm{c} 0} / \mathrm{NUE}_{j 0}}\right)^{0.5}$,

where $t_{\mathrm{c}, j_{0}}$ (unitless) is the ratio of Rubisco limited rate to light limited rate, $\mathrm{NUE}_{\mathrm{c} 0}\left(\mu \mathrm{mol} \mathrm{CO} \mathrm{s}^{-1} \mathrm{~g}^{-1} \mathrm{~N}\right)$ and $\mathrm{NUE}_{j 0}$ $\left(\mu \mathrm{mol} \mathrm{CO} \mathrm{s}^{-1} \mathrm{~g}^{-1} \mathrm{~N}\right)$ are the daily nitrogen use efficiency of $W_{\mathrm{c}}$ and $W_{j}$ under reference climate conditions defined as the $25^{\circ} \mathrm{C}$ leaf temperature and atmospheric $\mathrm{CO}_{2}$ concentration of $380 \mathrm{ppm}$, with leaf internal $\mathrm{CO}_{2}$ concentration set as $70 \%$ of the atmospheric $\mathrm{CO}_{2}$ concentration. $\mathrm{NUE}_{\mathrm{c}}$ $\left(\mu \mathrm{mol} \mathrm{CO} \mathrm{s}^{-1} \mathrm{~g}^{-1} \mathrm{~N}\right)$ and $\mathrm{NUE}_{j}\left(\mu \mathrm{molCO} \mathrm{C}_{2} \mathrm{~s}^{-1} \mathrm{~g}^{-1} \mathrm{~N}\right)$ are the nitrogen use efficiency of $W_{\mathrm{c}}$ and $W_{j}$ at the current climate conditions. See Eqs. (D6) and (D7) for details of calculation. The term $\frac{\mathrm{NUE}_{\mathrm{c}} / \mathrm{NUE}_{j}}{\mathrm{NUE}_{\mathrm{c} 0} / \mathrm{NUE}_{j 0}}$ assumes that the higher nitrogen use efficiency of $W_{\mathrm{c}}$ compared to that of $W_{j}$ will lead to a higher value of $t_{\mathrm{c}, j}$ given the same value of $W_{j}$. The exponent 0.5 is used to ensure that the response of $V_{\mathrm{c}, \max }$ to elevated
$\mathrm{CO}_{2}$ is down-regulated by approximately $10 \%$ when $\mathrm{CO}_{2}$ increased from 365 to $567 \mathrm{ppm}$ as reported by Ainsworth and Rogers (2007).

Replacing Eq. (A16) with Eqs. (A14), (A15) and (A17), we are able to estimate the maximum carboxylation rate $\left(V_{\mathrm{c}, \max } ; \mu \mathrm{mol} \mathrm{CO} \mathrm{CO}_{2} \mathrm{~m}^{-2} \mathrm{~s}^{-1}\right)$ as follows,

$V_{\mathrm{c}, \max }=t_{\mathrm{c}, j_{0}}\left(\frac{\mathrm{NUE}_{\mathrm{c}} / \mathrm{NUE}_{\mathrm{j}}}{\mathrm{NUE}_{\mathrm{c} 0} / \mathrm{NUE}_{j 0}}\right)^{0.5}\left(\frac{K_{j}}{K_{\mathrm{c}}}\right) J_{x}$.

Following Collatz et al. (1991), the total respiration $\left(R_{\mathrm{t}}\right)$ is calculated in proportion to $V_{\mathrm{c}, \max }$,

$R_{\mathrm{t}}=0.015 V_{\mathrm{c}, \max }$.

Accounting for the daytime and nighttime temperature, we are able to estimate the daily respiration as follows,

$R_{\text {td }}=R_{\mathrm{t}}\left[D_{\text {day }}+D_{\text {night }} f_{\mathrm{r}}\left(T_{\text {night }}\right) / f_{\mathrm{r}}\left(T_{\text {day }}\right)\right]$,

where $D_{\text {day }}$ and $D_{\text {night }}$ are daytime and nighttime durations in seconds. $f_{\mathrm{r}}\left(T_{\text {night }}\right)$ and $f_{\mathrm{r}}\left(T_{\text {day }}\right)$ are the temperature response functions for respiration (see Eq. B1 for details).

In summary, given an initial estimation of $N_{\text {lc }}$, we are able to first estimate the efficiency of light energy absorption $\alpha$ using Eq. (A12). With that, we are able to estimate the maximum electron transport rate, $J_{\max }$, using Eq. (A11). The nitrogen allocated for electron transport can thus be calculated as follows,

$N_{\mathrm{et}}=\frac{J_{\max }}{\mathrm{NUE}_{J_{\max }}}$.

Then, based on Eq. (A18), we are able to estimate the corresponding the maximum carboxylation rate $V_{\mathrm{c}, \max }$ and the nitrogen allocated for carboxylation as follows,

$N_{\mathrm{cb}}=\frac{V_{\mathrm{c}, \max }}{\mathrm{NUE}_{V_{\mathrm{c}, \max }}}$,

where $\mathrm{NUE}_{V_{\mathrm{c}, \max }}$ is the nitrogen use efficiency for $V_{\mathrm{c}, \max }$. See Eq. (D1) for details of calculation. Using Eq. (A20), we are able to estimate $R_{\mathrm{td}}$ and thus the nitrogen allocated for respiration as follows,

$N_{\text {resp }}=\frac{R_{\mathrm{td}}}{\mathrm{NUE}_{\mathrm{r}}}$,

where $\mathrm{NUE}_{\mathrm{r}}$ is nitrogen use efficiency of enzymes for respiration. See Eq. (D3) for details of calculation. Finally, the storage nitrogen is calculated as follows,

$N_{\text {store }}=\mathrm{FNC}_{\mathrm{a}}-N_{\text {resp }}-N_{\mathrm{cb}}-N_{\mathrm{lc}}-N_{\mathrm{et}}$.

Note that this storage nitrogen is mainly a remaining component of $\mathrm{FNC}_{\mathrm{a}}$. Its formulation is different from the formulation of Xu et al. (2012) where $N_{\text {store }}$ is set as a linear function of net photosynthetic rate. This modification is based on 
the observation that the preliminary fitting to data using the linear function shows no dependence of $N_{\text {store }}$ on net photosynthetic rate. To make the solutions realistic, we set the minimum of $N_{\text {store }}$ as $5 \%$ of $\mathrm{FNC}_{\mathrm{a}}$ in view of potential nitrogen for plant functionality that is not accounted for by photosynthesis and respiration. By exploring different values of nitrogen allocated for light capture $N_{\mathrm{lc}}$ and using the Eqs. (A21)-(A23), we will find the optimal nitrogen allocations $\left(\hat{N}_{\text {store, }} \hat{N}_{\text {resp }}, \hat{N}_{\text {lc }}, \hat{N}_{\text {et }}, \hat{N}_{\text {cb }}\right)$ until the net photosynthetic rate is maximized (see Eq. A5) given a specific set of nitrogen allocation coefficients (i.e., $J_{\operatorname{maxb} 0}, J_{\operatorname{maxb} 1}, H$, and $t_{\mathrm{c}, j_{0}}$ ). The detailed optimization algorithms are implemented as follows:

1. increase the nitrogen allocated $\left(N_{\mathrm{lc}}\right)$ for light capture (from a small initial value of 0.05 ) and calculate the corresponding light absorption rate $\alpha$ with Eq. (A12);

2. calculate $J_{\max }$ from Eq. (A11) and derive the nitrogen allocated to electron transport, $N_{\text {et }}$, using Eq. (A21);

3. calculate $V_{\mathrm{c}, \max }$ from Eq. (A18) and derive the nitrogen allocated to Rubisco, $N_{\mathrm{cb}}$, using Eq. (A22);

4. calculate the total respiration $R_{\mathrm{td}}$ from Eq. (A20) and derive the nitrogen allocated to respiration, $N_{\text {resp }}$, using Eq. (A23);

5. calculate the total nitrogen invest in photosynthetic enzymes including nitrogen for electron transport, carboxylation and light capture using Eq. (A2);

6. calculate the gross photosynthetic rate, $A$, and the maintenance respiration for photosynthetic enzymes, $R_{\mathrm{psn}}$, by Eq. (A6);

7. repeat steps (1) to (6) until the increase from previous time step in $A$ is smaller than or equal to the increase in $R_{\mathrm{psn}}$.

Since the response of $V_{\mathrm{c}, \max }$ and $J_{\max }$ to increasing temperature shows a steady rise to an optimum followed by a relatively rapid decline (Bernacchi et al., 2003; Kattge and Knorr, 2007; Leuning, 2002; Medlyn et al., 2002a), we postulate that the detrimental heat stress on leaf enzymatic activity beyond this optimum (Crafts-Brandner and Law, 2000; Crafts-Brandner and Salvucci, 2000; Law and CraftsBrandner, 1999; Spreitzer and Salvucci, 2002) will cause the leaf to fail to optimize its nitrogen allocation. Consequently, we hypothesized that plants only optimize nitrogen allocation up to their optimum enzymatic activity, which is $42^{\circ} \mathrm{C}$ for TRF1 and $33^{\circ} \mathrm{C}$ for TRF2. Regardless of whether plants acclimate to temperature or not, we assume that they do not optimally allocate nitrogen when leaf temperature is below $5^{\circ} \mathrm{C}$ because low temperatures could substantially limit plant enzymes (Martin et al., 1978; Öquist et al., 1980; Strand and Öquist, 1988).
After we get the optimal nitrogen allocations $\left(\hat{N}_{\text {store, }} \hat{N}_{\text {resp }}, \hat{N}_{\text {lc }}, \hat{N}_{\text {et, }} \hat{N}_{\text {cb }}\right)$, we are able to estimate the $V_{\mathrm{c}, \max 25}$ and $J_{\max 25}$ by rearranging Eqs. (A21) and (A22) as follows:

$V_{\mathrm{c}, \max 25}=\hat{N}_{\mathrm{cb}} \mathrm{NUE}_{V_{\mathrm{c}, \max 25}}$,

$J_{\max 25}=\hat{N}_{\mathrm{cb}} \mathrm{NUE}_{J_{\max 25}}$,

where $\mathrm{NUE}_{V_{c, \max 25}}$ and $\mathrm{NUE}_{J_{\max 25}}$ are the nitrogen use efficiency for $V_{\mathrm{c}, \max 25}$ and $J_{\max 25}$. See Eqs. (D1) and (D2) in Appendix D for details of calculations.

\section{Appendix B: Temperature response functions}

\section{B1 Temperature dependence of Rubisco properties and respiration}

The temperature dependence of Rubisco kinetic parameters $\left(K_{\mathrm{c}}, K_{\mathrm{o}}, \tau\right)$ and mitochondrial respiration in light $\left(R_{\mathrm{d}}\right)$ (Farquhar et al., 1980) is an Arrhenius function taken from Bernacchi et al. (2001). The temperature response functions of Rubisco kinetic parameters used are outlined below, which are the same irrespective of whether plants are assumed to acclimate to growth temperatures (Temperature response function one; TRF1) or not (Temperature response function two; TRF2).

Community land model version 4.5 (CLM4.5) (Oleson et al., 2013) uses the partial pressures of oxygen, $O$ as $20900 \mathrm{~Pa}$. The kinetic properties of Rubisco, which depend on temperature are Rubisco-specific factor, $\tau$ (Jordan and Ogren, 1984), $K_{\mathrm{cc}}$ and $K_{\mathrm{o}}$, which are the Michaelis-Menten constants for $\mathrm{CO}_{2}$ and $\mathrm{O}_{2}$, respectively. The temperature response function of $R_{\mathrm{d}}$ and kinetic properties of Rubisco $\left(K_{\mathrm{cc}}\right.$, $\left.K_{\mathrm{o}}, \tau\right)$ are described below, where the fixed coefficients of the equations are values at $25^{\circ} \mathrm{C}$.

$$
\begin{aligned}
& f_{\mathrm{r}}\left(T_{1}\right)=e^{\left[\left(46390 / R T_{0}\right)\left(1-T_{0} / T_{1}\right)\right]} \\
& K_{0}\left(T_{1}\right)=27840 e^{\left[\left(36380 / R T_{0}\right)\left(1-T_{0} / T_{1}\right)\right]} \\
& K_{\mathrm{c}}\left(T_{1}\right)=40.49 e^{\left[\left(79430 / R T_{0}\right)\left(1-T_{0} / T_{1}\right)\right]} \\
& \tau\left(T_{1}\right)=2407.834 e^{\left[\left(37830 / R T_{0}\right)\left(1-T_{0} / T_{1}\right)\right]}
\end{aligned}
$$

In the above equations, $R$ is the universal gas constant $\left(8.314 \mathrm{~J} \mathrm{~mol}^{-1} \mathrm{~K}^{-1}\right), T_{1}$ is the leaf temperature $(K)$ and the reference temperature, $T_{0}=298.15 \mathrm{~K}$.

\section{B2 Temperature dependence of $V_{c, \max }$ and $J_{\max }$}

Temperature sensitivities of $V_{\mathrm{c}, \max }$ and $J_{\max }$ are simulated using a modified Arrhenius function (e.g., Kattge and Knorr, 2007; Medlyn et al., 2002a; Walker et al., 2014). Because the temperature relationship could acclimate, we examined Kattge and Knorr (2007)'s formulation of with and without temperature acclimation to plant growth temperature. We use two temperature dependence functions of $V_{\mathrm{c}, \max }$ and $J_{\max }$, which are described below. 


\section{B3 Temperature response function one (TRF1)}

Fundamentally, TRF1 is a temperature dependence function for $V_{\mathrm{c}, \max }$ and $J_{\max }$, which is based on the formulation and parameterization as in Medlyn et al. (2002a) but further modified by Kattge and Knorr (2007) to make the temperature optima a function of growth temperature $\left(T_{\mathrm{g}} ;{ }^{\circ} \mathrm{C}\right)$. It is specified for $V_{\mathrm{c}, \max }$ as follows:

$V_{\mathrm{c}, \max }\left(T_{1}, T_{\mathrm{g}}\right)=V_{\mathrm{c}, \max 25} f_{V_{\mathrm{c}, \max }}\left(T_{1}, T_{\mathrm{g}}\right)$,

with

$$
\begin{aligned}
& f_{V_{\mathrm{c}, \max }}\left(T_{1}, T_{\mathrm{g}}\right)= \\
& \frac{\left(1+e^{\left[\left(S_{v} T_{0}-H_{\mathrm{d}}\right) /\left(R T_{0}\right)\right]}\right) e^{\left[\left(H_{\mathrm{a}} / R T_{0}\right)\left(1-T_{0} / T_{1}\right)\right]}}{1+e^{\left[\left(S_{v} T_{1}-H_{\mathrm{d}}\right) /\left(R T_{1}\right)\right]}},
\end{aligned}
$$

where $V_{\mathrm{c}, \max 25}$ is the value of $V_{\mathrm{c}, \max }$ at the reference temperature $\left(T_{0}=298.15 \mathrm{~K}\right) . H_{\mathrm{a}}\left(\mathrm{J} \mathrm{mol}^{-1}\right)$ is energy of activation and $H_{\mathrm{d}}\left(\mathrm{J} \mathrm{mol}^{-1}\right)$ is the energy of deactivation. $R$ is the universal gas constant $\left(8.314 \mathrm{~J} \mathrm{~mol}^{-1} \mathrm{~K}^{-1}\right)$ and $T_{1}(K)$ is the leaf temperature. The entropy term, $S_{v}\left(\mathrm{~J} \mathrm{~mol}^{-1} \mathrm{~K}^{-1}\right)$, is now a function of temperature (Kattge and Knorr, 2007),

$S_{v}=a+b T_{\mathrm{g}}$,

where $a$ and $b$ are acclimation parameters.

TRF1 is implemented in CLM4.5 by Oleson et al. (2013), who use the form of temperature dependence function for $V_{\mathrm{c}, \max }$ and $J_{\max }$ as shown in Eq. (B5), but with limited temperature acclimation, where $S_{v}=668.39-$ $1.07 \min \left(\max \left(T_{\mathrm{g}}, 11\right), 35\right)$ with $T_{\mathrm{g}}$ representing the monthly mean air temperature $\left({ }^{\circ} \mathrm{C}\right)$. Other parameters present in CLM4.5 model include, $H_{\mathrm{a}}=72000 \mathrm{~J} \mathrm{~mol}^{-1}$ and $H_{\mathrm{d}}=$ $200000 \mathrm{~J} \mathrm{~mol}^{-1}$. The values of the acclimation parameters ( $a=668.39$ and $b=-1.07$ ) are taken from Table 3 of Kattge and Knorr (2007).

An equation similar to Eq. (B6), $f_{J_{\max }}\left(T_{1}, T_{\mathrm{g}}\right)$, is used to describe the temperature dependence of $J_{\max }$ that considers temperature acclimation based on the $S_{v}$ term. The values of the acclimation parameters ( $a$ and $b$ ) for $S_{v}$ are taken from Table 3 of Kattge and Knorr (2007). Following Kattge and Knorr (2007) and CLM4.5, we set $H_{\mathrm{a}}$ and $H_{\mathrm{d}}$ for $J_{\max }$ as 50000 and $200000 \mathrm{~J} \mathrm{~mol}^{-1}$, respectively.

\section{B4 Temperature response function two (TRF2)}

TRF2 does not consider the thermal acclimation. The formulation of TRF2 is same as TRF1 except that in TRF2, the entropy term; $S_{v}\left(\mathrm{~J} \mathrm{~mol}^{-1} \mathrm{~K}^{-1}\right)$ is fixed across our data set. The values of $S_{v}$ are taken from Table 3 of Kattge and Knorr (2007). $S_{v}$ is set as $649.12 \mathrm{~J} \mathrm{~mol}^{-1} \mathrm{~K}^{-1}$ and $646.22 \mathrm{~J} \mathrm{~mol}^{-1} \mathrm{~K}^{-1}$ for $V_{\mathrm{c}, \max 25}$ and $J_{\max 25}$, respectively.

\section{Appendix C: The Farquhar photosynthesis and Ball-Berry model}

\section{C1 Overview}

Photosynthesis is described using a system of three equations and three unknown variables. The three unknown variables include (1) the net rate of leaf photosynthesis $(A),(2)$ the stomatal conductance $\left(g_{\mathrm{s}}\right)$ and (3) the intercellular partial pressure of $\mathrm{CO}_{2}\left(C_{i}\right)$. All of the unknown variables influence one another. The three equations include (1) the Farquhar's non-linear equation ( $A$ vs. $C_{i}$ ), (2) the Ball-Berry equation $\left(g_{\mathrm{s}}\right.$ vs. $\left.A\right)$ and (3) the diffusion equation $\left(A=g_{\mathrm{s}}\left(C_{\mathrm{a}}-C_{i}\right)\right)$. We solved all of these equations simultaneously by taking an iterative approach (Collatz et al., 1991; Harley et al., 1992; Leuning, 1990). The detailed algorithm for modeling photosynthesis is described below.

\section{C2 Modeling photosynthesis}

The photosynthetic rate $(A)$ depends upon (i) the amount, activity and kinetic properties of Rubisco, and (ii) the rate of ribulose-1,5 bisphosphate (RuBP) regeneration via electron transport (Farquhar et al., 1980). The minimum of these two limiting conditions yields the following expression,

$A=\min \left(W_{\mathrm{c}}, W_{\mathrm{j}}\right)$,

where $W_{\mathrm{c}}$ is the Rubisco limited rate and $W_{\mathrm{j}}$ is the electron transport limited rate. The Rubisco-limited carboxylation can be described by

$W_{\mathrm{c}}=K_{\mathrm{c}} V_{\mathrm{c}, \max }$,

with

$K_{\mathrm{c}}=\frac{\max \left(0, C_{i}-\frac{0.5 O}{\tau}\right)}{C_{i}+K_{\mathrm{cc}}\left(1+O / K_{\mathrm{o}}\right)}$,

where $V_{\mathrm{c}, \max }$ is the maximum rate of carboxylation, competitive with respect to both $\mathrm{CO}_{2}$ and oxygen, and $K_{\mathrm{cc}}$ and $K_{\mathrm{o}}$ are Michaelis constants for carboxylation and oxygenation, respectively. $\tau$ is the specificity factor for Rubisco (Jordan and Ogren, 1984), while $C_{i}$ and $O$ are the partial pressures of $\mathrm{CO}_{2}$ and $\mathrm{O}_{2}$ in the intercellular air space, respectively. Likewise, the electron-limited rate of carboxylation can be expressed by

$W_{\mathrm{j}}=K_{\mathrm{j}} J$,

with

$K_{\mathrm{j}}=\frac{\max \left(0, C_{\mathrm{i}}-\frac{0.5 O}{\tau}\right)}{4\left(C_{\mathrm{i}}+2 \frac{0.5 O}{\tau}\right)}$,

where $J$ is the potential rate of electron transport, and the factor 4 indicates that the transport of four electrons will generate sufficient ATP and NADPH for the regeneration of RuBP 
in the Calvin cycle (Farquhar and von Caemmerer, 1982). The potential rate of electron transport is dependent upon irradiance, $I$, according to the empirical expression of Smith (1937):

$J=\frac{\alpha I}{\left(1+\frac{\alpha^{2} I^{2}}{J_{\max }^{2}}\right)^{1 / 2}}$,

where $\alpha$, the efficiency of light energy conversion is considered as 0.292 (unitless) (Niinemets and Tenhunen, 1997) and $J_{\max } i s$ the maximum rate of electron transport.

\section{C3 Ball-Berry model}

The stomatal conductance $\left(g, \mathrm{~m} \mathrm{~s}^{-1}\right)$ is evaluated by the Ball-Berry empirical stomatal conductance model (Ball et al., 1987):

$g_{\mathrm{s}}=g_{0}+m \frac{A \mathrm{RH}}{C_{\mathrm{a}}}$,

where RH is the relative humidity (unitless) at the leaf surface, $C_{\mathrm{a}}$ is the $\mathrm{CO}_{2}$ concentration at the leaf surface, and $g_{0}\left(0.0005 \mathrm{~m} \mathrm{~s}^{-1}\right)$ and $m$ are the minimum stomatal conductance and slope (9; constant across all $\mathrm{C}_{3}$ species), respectively.

The estimation of $A$ could be sensitive to the choice of maximum stomatal conductance slope, as this parameter varies both within and across species (Harley and Baldocchi, 1995; Wilson et al., 2001). A recent synthesis provides the first analysis of the global variation in stomatal slope based on an alternative algorithm that considers representation of optimal stomatal behavior (Lin et al., 2015). However, following CLM4.5, which uses the Ball-Berry empirical stomatal conductance model (Ball et al., 1987), we fixed the value of stomatal slope $(m)$ as 9 for all PFTs in our study.

\section{C4 Calculation of photosynthesis and stomatal conductance}

We solved Farquhar's non-linear equation $\left(A\right.$ vs. $\left.C_{i}\right)$, the Ball-Berry equation ( $g_{\mathrm{s}}$ vs. $A$ ) and the diffusion equation ( $A=g_{\mathrm{s}}\left(C_{\mathrm{a}}-C_{i}\right)$ simultaneously by taking an iterative approach (Collatz et al., 1991; Harley et al., 1992; Leuning, 1990) until values of $A, g_{\mathrm{s}}$ and $C_{i}$ are obtained. The three equations are solved in two phases; the first phase included solving the equations for which Rubisco is limiting while the second phase considered light limitation. The following steps are followed:

1. Given the initial values of $C_{i}$ (where initial value of $\mathrm{C}_{i}$ is assumed $0.7 \times$ ambient $\mathrm{CO}_{2}$ concentration), the temperature dependence functions of $V_{\mathrm{c}, \max }$ and $J_{\max }$ (see Appendix B), and the temperature dependence of Rubisco kinetics ( $O, \tau, K_{c}$ and $K_{o}$, Appendix B), $A$ is calculated from Eq. (C2).
2. $\mathrm{CO}_{2}$ concentration at the leaf surface $\left(C_{\mathrm{a}}\right)$ is determined by calculating the difference between $C_{i}$ and the partial pressure due to $A$, wind speed and the dimension of the leaf.

3. Given $A$ and $C_{\mathrm{a}}$, the stomatal conductance $\left(g_{\mathrm{s}}\right)$ is determined using Eq. (C8).

4. $C_{i}$ is determined by calculating the difference between $C_{\mathrm{a}}$ and partial pressure due to $A$ and boundary conditions of the stomata.

5. Using the leaf energy balance based on absorbed shortwave radiation, molar latent heat content of water vapor, air temperature, and a parameter that governs the rate of convective cooling (38.4 $\mathrm{J} \mathrm{m}^{-2} \mathrm{~s}^{-1} \mathrm{~K}^{-1}$ ) (Jarvis, 1986; Moorcroft et al., 2001), leaf temperature is calculated.

The above five steps are repeated in a systematic way until $C_{i}$ is equilibrated and the final value of $A$ is then recorded. The net photosynthetic rate, $A_{\text {net }}$, is then calculated by subtracting the respiration from $A$ as follows:

$A_{\text {net }}=A-R_{\mathrm{t}}$,

where $R_{\mathrm{t}}$ is respiration calculated by Eq. (A19).

\section{Appendix D: Nitrogen use efficiencies}

The nitrogen use efficiency for $V_{\mathrm{c}, \max } \quad\left(\mathrm{NUE}_{V_{c, \max }}\right.$, $\mu \mathrm{mol} \mathrm{CO} 2 \mathrm{~g}^{-1} \mathrm{~N} \mathrm{~s}^{-1}$ ) is estimated from a baseline nitrogen use efficiency $25^{\circ} \mathrm{C}\left(\mathrm{NUE}_{V_{\mathrm{c}, \max 25}}\right)$ and a corresponding temperature response function at as follows:

$\mathrm{NUE}_{V_{\mathrm{c}, \text { max }}}=\mathrm{NUE}_{V_{\mathrm{c}, \text { max } 25}} \times f_{V_{\mathrm{c}, \text { max }}}\left(T, T_{\mathrm{g}}\right)$

with

$\mathrm{NUE}_{V_{\mathrm{c}, \max 25}}=47.3 \times 6.25$,

where the constant 47.3 is the specific Rubisco activity $\left(\mu \mathrm{mol} \mathrm{CO} \mathrm{CO}^{-1}\right.$ Rubisco s ${ }^{-1}$ ) measured at $25^{\circ} \mathrm{C}$ and the constant 6.25 is the nitrogen binding factor for Rubisco $\left(g\right.$ Rubisco $\left.\mathrm{g}^{-1} \mathrm{~N}\right)$ (Rogers, 2014). $f_{V_{\mathrm{c}, \max }}\left(T, T_{\mathrm{g}}\right)$ is the function specifying the temperature dependence of $V_{\mathrm{c} \text {,max }}$ with $T$ as the leaf temperature $(\mathrm{K})$ and $T_{\mathrm{g}}$ as the growth air temperature (see Appendix B for details of the temperature dependence of $\left.V_{\mathrm{c}, \max }\right)$.

The nitrogen use efficiency for $J_{\max }\left(\mathrm{NUE}_{J_{\max }}\right.$, $\mu$ mol electron $\mathrm{g}^{-1} \mathrm{~N} \mathrm{~s}^{-1}$ ) is estimated based on a characteristic protein cytochrome $f$ (Evans and Poorter, 2001),

$\mathrm{NUE}_{J_{\max }}=\mathrm{NUE}_{J_{\max 25}} \times f_{J_{\max }}\left(T, T_{\mathrm{g}}\right)$,

with

$\mathrm{NUE}_{J_{\max 25}}=8.06 \times 156$ 
where the coefficient 156 is the maximum electron transport rate for cytochrome $f$ at $25^{\circ} \mathrm{C}$ ( $\mu \mathrm{mol}$ electron/ $\mu \mathrm{mol}$ cytochrome $f$ ); 8.06 is the nitrogen binding coefficient for cytochrome $f$ ( $\mu$ mol cytochrome $f \mathrm{~g}^{-1} \mathrm{~N}$ in bioenergetics). $f_{J_{\max }}\left(T, T_{\mathrm{g}}\right)$ is a function specifies the dependence of $J_{\max }$ on temperature (see Appendix B for details of the temperature dependence of $\left.J_{\max }\right)$.

The nitrogen use efficiency of enzymes for respiration $\left(\mu \mathrm{mol} \mathrm{CO} \mathrm{C}_{2} \mathrm{~g}^{-1} \mathrm{Nday}^{-1}\right.$ ), $\mathrm{NUE}_{\mathrm{r}}$, is assumed to be temperature-dependent. Specifically, it is calculated as follows,

$\mathrm{NUE}_{\mathrm{r}}=33.69\left[D_{\text {day }} f_{\mathrm{r}}\left(T_{\text {day }}\right)+D_{\text {night }} f_{\mathrm{r}}\left(T_{\text {night }}\right)\right]$,

where 33.69 is the specific nitrogen use efficiency for respiration at $25^{\circ} \mathrm{C}\left(\mu \mathrm{mol} \mathrm{CO} \mathrm{g}^{-1} \mathrm{~N} \mathrm{~s}^{-1}\right)$ (Makino and Osmond, 1991) and $f_{\mathrm{r}}(T)$ specifies the dependence of respiration on temperature. $D_{\text {day }}$ and $D_{\text {night }}$ is the daytime and nighttime length in seconds.

The maintenance respiration cost for all photosynthetic enzymes ( $\mathrm{NUE}_{\mathrm{rp}}, \mu \mathrm{mol} \mathrm{CO}_{2} \mathrm{~g}^{-1} \mathrm{~N} \mathrm{~s}^{-1}$ ) is calculated as follows:

$\mathrm{NUE}_{\mathrm{rp}}=\mathrm{NUE}_{\mathrm{rp} 25} f_{\mathrm{r}}\left(T, T_{\mathrm{g}}\right)$,

where $\mathrm{NUE}_{\mathrm{rp} 25}$ is the nitrogen use efficiency at $25^{\circ} \mathrm{C}$. $\mathrm{NUE}_{\mathrm{rp} 25}$ is estimated from the observation of $J_{\max 25}$ and $V_{\mathrm{c}, \max 25}$ as follows:

$\mathrm{NUE}_{\mathrm{rp} 25}=\frac{0.8 \times 0.5 \times 0.015 \times V_{\mathrm{c}, \max 25}}{\frac{J_{\max 25}}{\mathrm{NUE} J_{\max 25}}+\frac{V_{\mathrm{c}, \max 25}}{\mathrm{NUE} E_{V_{\mathrm{c}, \max 25}}}+0.2}$,

where the total respiration is set as $1.5 \%$ of $V_{\mathrm{c}, \max }$ (Collatz et al., 1991). We assume that $50 \%$ of the total respiration is used for maintenance respiration (Van Oijen et al., 2010) and $80 \%$ of the maintenance respiration is used for photosynthetic enzyme. In view that the light absorption rate is generally around $80 \%$ (Evans and Poorter, 2001), we set the nitrogen for light capture as 0.2 based on Eq. (A12) in Appendix A. $\mathrm{NUE}_{J_{\max 25}}$ and $\mathrm{NUE}_{V_{\mathrm{c}, \max 25}}$ are the nitrogen use efficiency for $J_{\max 25}$ and $V_{\mathrm{c}, \max 25}$ estimated from Eqs. (D1) and (D2). In this study, we use the estimated mean value of 0.715 for $\mathrm{NUE}_{\mathrm{rp} 25}$ based on the data of Ali et al. (2015).
The nitrogen use efficiency for carboxylation $\left(\mathrm{NUE}_{\mathrm{c}}\right)$ is calculated as the multiplication of conversion factor $K_{\mathrm{c}}$ and the nitrogen use efficiency for $V_{\mathrm{c}, \max }$ follows:

$\mathrm{NUE}_{\mathrm{c}}=K_{\mathrm{c}} \mathrm{NUE}_{V_{\mathrm{c}, \max }}$,

where $K_{\mathrm{c}}$ is calculated based on the actual internal $\mathrm{CO}_{2}$ concentrations and leaf temperature (see Eq. $\mathrm{C} 4$ for details). Correspondingly, the reference nitrogen use efficiency for carboxylation $\left(\mathrm{NUE}_{\mathrm{c} 0}\right)$ is calculated using the Eq. (D5) except that $K_{\mathrm{c}}$ is calculated based on the reference internal $\mathrm{CO}_{2}$ concentration of $26.95 \mathrm{~Pa}$ and the reference leaf temperature of $25^{\circ} \mathrm{C}$. The reference internal $\mathrm{CO}_{2}$ concentration is estimated by assuming $70 \%$ of the atmospheric $\mathrm{CO}_{2}$ concentration of $380 \mathrm{ppm}$ and an air pressure of $101,325 \mathrm{~Pa}$.

The nitrogen use efficiency for electron transport $\left(\mathrm{NUE}_{j}\right)$ is calculated as the multiplication of conversion factor $K_{j}$ and the nitrogen use efficiency for $J_{\max }$ follows:

$\mathrm{NUE}_{j}=K_{j} \mathrm{NUE}_{J_{\max }}$,

where $K_{j}$ is calculated based on the actual internal $\mathrm{CO}_{2}$ concentrations and leaf temperature (see Eq. C6 in Appendix C for details). Correspondingly, the reference nitrogen use efficiency for electron transport $\left(\mathrm{NUE}_{j 0}\right)$ is calculated using the Eq. (D6) except that $K_{j}$ is calculated based on the reference internal $\mathrm{CO}_{2}$ concentration of $26.95 \mathrm{~Pa}$ and the reference leaf temperature of $25^{\circ} \mathrm{C}$. The reference internal $\mathrm{CO}_{2}$ concentration is estimated by assuming $70 \%$ of the atmospheric $\mathrm{CO}_{2}$ concentration of $380 \mathrm{ppm}$ and an air pressure of 101, $325 \mathrm{~Pa}$. 


\section{The Supplement related to this article is available online at doi:10.5194/gmd-9-587-2016-supplement.}

Acknowledgements. This work is funded by UC Lab Research Program (ID: 237285) and by the DOE Office of Science, Next Generation Ecosystem Experiment (NGEE) programs in the arctic and in the tropics. This submission is under public release with the approved LA-UR-14-23309.

Edited by: G. A. Folberth

\section{References}

Ainsworth, E. A. and Rogers, A.: The response of photosynthesis and stomatal conductance to rising $\left(\mathrm{CO}_{2}\right)$ : mechanisms and environmental interactions, Plant Cell Environ., 30, 258-270, 2007.

Ali, A. A., Xu, C., Rogers, A., McDowell, N. G., Medlyn, B. E., Fisher, R. A., Wullschleger, S. D., Reich, P. B., Vrugt, J. A., Bauerle, W. L., Santiago, L. S., and Wilson, C. J.: Global scale environmental control of plant photosynthetic capacity, Ecol. Appl., 25, 2349-2365, doi:10.1890/14-2111.1, 2015, 2015.

Ball, J. T., Woodrow, I. E., and Berry, J. A.: A model predicting stomatal conductance and its contribution to the control of photosynthesis under different environmental conditions, Dordrecht, The Netherlands, 221-224, 1987.

Bauerle, W. L., Oren, R., Way, D. A., Qian, S. S., Stoy, P. C., Thornton, P. E., Bowden, J. D., Hoffman, F. M., and Reynolds, R. F.: Photoperiodic regulation of the seasonal pattern of photosynthetic capacity and the implications for carbon cycling, Proc. Natl. Acad. Sci. USA, 109, 8612-8617, 2012.

Bernacchi, C. J., Singsaas, E. L., Pimentel, C., Portis Jr., A. R., and Long, S. P.: Improved temperature response functions for models of Rubisco-limited photosynthesis, Plant Cell Environ., 24, 253259, 2001

Bernacchi, C. J., Pimentel, C., and Long, S. P.: In vivo temperature response functions of parameters required to model RuBPlimited photosynthesis, Plant Cell Environ., 26, 1419-1430, 2003.

Block, K. and Mauritsen, T.: Forcing and feedback in the MPIESM-LR coupled model under abruptly quadrupled $\mathrm{CO}_{2}$, J. Adv. Model. Earth Syst., 5, 676-691, 2013.

Bonan, G. B., Levis, S., Sitch, S., Vertenstein, M., and Oelson, K. W.: A dynamic global vegetation model for use with climate models: concepts and description of simulated vegetation dynamics, Glob. Change Biol., 9, 1543-1566, 2003.

Bonan, G. B., Lawrence, P. J., Oleson, K. W., Levis, S., Jung, M., Reichstein, M., Lawrence, D. M., and Swenson, S. C.: Improving canopy processes in the community land model version 4 (CLM4) using global flux fields empirically inferred from FLUXNET data, J. Geophys. Res., 116, 1-22, 2011.

Breshears, D. D., Myers, O. B., Meyer, C. W., Barnes, F. J., Zou, C. B., Allen, C. D., McDowell, N. G., and Pockman, W. T.: Tree die-off in response to global change-type drought: mortality insights from a decade of plant water potential measurements, Front. Ecol. Environ., 7, 185-189, 2008.
Canadell, J. G., Le Quéré, C., Raupach, M. R., Field, C. B., Buitenhuis, E. T., Ciais, P., Conway, T. J., Gillett, N. P., Houghton, R. A., and Marland, G.: Contributions to accelerating atmospheric $\mathrm{CO}_{2}$ growth from economic activity, carbon intensity, and efficiency of natural sinks, Proc. Natl. Acad. Sci. USA, 104, 1886618870, 2007

Cernusak, L. A., Winter, K., and Turner, B. L.: Leaf nitrogen to phosphorus ratios of tropical trees: experimental assessment of physiological and environmental controls, New Phytol., 185, 770-779, 2010.

Collatz, G. J., Ball, J. T., Grivet, C., and Berry, J. A.: Physiological and environmental regualtion of stomatal conductance, photosynthesis, and transpiration: A model that includes a laminar boundary layer, Agr. Forest Meteorol., 54, 107-136, 1991.

Comstock, J. and Ehleringer, J. R.: Photoperiod and photosynthetic capacity in Lotus scoparius, Plant Cell Environ., 9, 609-612, 1986.

Cowan, I. and Farquhar, G.: Stomatal function in relation to leaf metabolism and environment, 471-505, 1977.

Crafts-Brandner, S. J. and Law, R. D.: Effect of heat stress on the inhibition and recovery of ribulose-1,5-bisphosphate carboxylase/oxygenase activation state, Planta, 212, 67-74, 2000.

Crafts-Brandner, S. J. and Salvucci, M. E.: Rubisco activase constrains the photosynthetic potential of leaves at high temperature and $\mathrm{CO}_{2}$, Proc. Natl. Acad. Sci. USA, 97, 13430-13435, 2000.

Dewar, R. C.: Maximum entropy production and plant optimization theories, Philos. T. Roy. Soc. B, 365, 1429-1435, 2010.

Dubois, J.-J. B., Fiscus, E. L., Booker, F. L., Flowers, M. D., and Reid, C. D.: Optimizing the statistical estimation of the parameters of the Farquhar-von Caemmerer-Berry model of photosynthesis, New Phytol., 176, 402-414, 2007.

Evans, J. R. and Poorter, H.: Photosynthetic acclimation of plants to growth irradiance: the relative importance of specific leaf area and nitrogen partitioning in maximizing carbon gain, Plant Cell Environ., 24, 755-767, 2001.

Farquhar, G. D. and von Caemmerer, S. (Eds.): Modelling of photosynthetic response to environmental conditions, HeidelbergBerlin-New York, Springer-Verlag, 1982.

Farquhar, G. D., Von Caemmerer, S., and Berry, J.: A biochemical model of photosynthetic $\mathrm{CO}_{2}$ assimilation in leaves of $\mathrm{C}_{3}$ species, Planta, 149, 78-90, 1980.

Franklin, O., Johansson, J., Dewar, R. C., Dieckmann, U., McMurtrie, R. E., Brännström, Å., and Dybzinski, R.: Modeling carbon allocation in trees: a search for principles, Tree Physiol., 32, 648666, 2012.

Friedlingstein, P., Meinshausen, M., Arora, V. K., Jones, C. D., Anav, A., Liddicoat, S. K., and Knutti, R.: Uncertainties in CMIP5 climate projections due to carbon cycle feedbacks, J. Climate, 27, 511-526, 2014.

Friend, A.: Use of a model of photosynthesis and leaf microenvironment to predict optimal stomatal conductance and leaf nitrogen partitioning, Plant Cell Environ., 14, 895-905, 1991.

Gent, P. R., Danabasoglu, G., Donner, L. J., Holland, M. M., Hunke, E. C., Jayne, S. R., Lawrence, D. M., Neale, R. B., Rasch, P. J., and Vertenstein, M.: The community climate system model version 4, J. Climate, 24, 4973-4991, 2011.

Goll, D. S., Brovkin, V., Parida, B. R., Reick, C. H., Kattge, J., Reich, P. B., van Bodegom, P. M., and Niinemets, Ü.: Nutrient limitation reduces land carbon uptake in simulations with a model 
of combined carbon, nitrogen and phosphorus cycling, Biogeosciences, 9, 3547-3569, doi:10.5194/bg-9-3547-2012, 2012.

Hanson, P. J., Amthor, J. S., Wullschleger, S. D., Wilson, K. B., Grant, R. F., Hartley, A., Hui, D., Hunt, J. E. R., Johnson, D. W., Kimball, J. S., King, A. W., Luo, Y., McNulty, S. G., Sun, G., Thornton, P. E., Wang, S., Williams, M., Baldocchi, D. D., and Cushman, R. M.: Oak forest carbon and water simulations: model intercomparisons and evaluations against independent data, Ecol. Monogr., 74, 443-489, 2004.

Harley, P. C. and Baldocchi, D. D.: Scaling carbon dioxide and water vapour exchange from leaf to canopy in a decisuous forest. I. Leaf model parametrization, Plant Cell Environ., 18, 1146-1156, 1995.

Harley, P. C., Thomas, R. B., Reynolds, J. F., and Strain, B. R.: Modelling photosynthesis of cotton grown in elevated $\mathrm{CO}_{2}$, Plant Cell Environ., 15, 271-282, 1992.

Haxeltine, A. and Prentice, I. C.: A general model for the lightuse efficiency of primary production, Funct. Eocol., 10, 551-561, 1996.

Houlton, B. Z., Marklein, A. R., and Bai, E.: Representation of nitrogen in climate change forecasts, Nature Clim. Change, 5, 398$401,2015$.

Hurrell, J. W., Holland, M. M., Gent, P. R., Ghan, S., Kay, J. E., Kushner, P. J., Lamarque, J. F., Large, W. G., Lawrence, D., Lindsay, K., Lipscomb, W. H., Long, M. C., Mahowald, N., Marsh, D. R., Neale, R. B., Rasch, P., Vavrus, S., Vertenstein, M., Bader, D., Collins, W. D., Hack, J. J., Kiehl, J., and Marshall, S.: The Community Earth System Model: A Framework for Collaborative Research, B. Am. Meteorol. Soc., 94, 1339-1360, 2013.

Jarvis, P. G.: Coupling of carbon and water interactions in forest stands, Tree Physiol., 2, 347-368, 1986.

Jordan, D. B. and Ogren, W. L.: The $\mathrm{CO}_{2} / \mathrm{O}_{2}$ specificity of ribulose 1,5-biphosphate carboxylase/oxygenase. Dependence on ribulose-biphosphate concentration, $\mathrm{pH}$ and temperature, Planta, 161, 308-313, 1984.

Kattge, J. and Knorr, W.: Temperature acclimation in a biochemical model of photosynthesis: a reanalysis of data from 36 species, Plant Cell Environ., 30, 1176-1190, 2007.

Kattge, J., Knorr, W., Raddatz, T., and Wirth, C.: Quantifying photosynthetic capacity and its relationship to leaf nitrogen content for global-scale terrestrial biosphere models, Glob. Change Biol., 15, 976-991, 2009.

Knorr, W. and Kattge, J.: Inversion of terrestrial ecosystem model parameter values against eddy covariance measurements by Monte Carlo sampling, Glob. Change Biol., 11, 1333-1351, 2005.

Laloy, E. and Vrugt, J. A.: High-dimensional posterior exploration of hydroligic models using multiple-try $\operatorname{DREAM}(z s)$ and high-performance computing, Water Resour. Res., 48, W01526, doi:01510.01029/02011WR010608, 2012.

Law, R. D. and Crafts-Brandner, S. J.: Inhibition and acclimation of photosynthesis to heat stress is closely correlated with activation of ribulose-1,5-bisphosphate carboxylase/ oxygenase, Plant Physiol., 120, 173-181, 1999.

Leuning, R.: Modeling stomatal behavior and photosynthesis of Eucalyptus grandis, Austr. J. Plant Physiol., 17, 159-175, 1990.

Leuning, R.: Scaling to a common temperature improves the correlation between photosynthesis parameters $\mathrm{J}_{\max }$ and $\mathrm{V}_{\mathrm{cmax}}$, J. Exp. Bot., 307, 345-347, 1997.
Leuning, R.: Temperature dependence of two parameters in a photosynthesis model, Plant Cell Environ., 25, 1205-1210, 2002.

Limousin, J.-M., Misson, L., Lavoir, A.-V., Martin, N. K., and Rambal, S.: Do photosynthetic limitations of evergreen Quercus ilex leaves change with long-term increased drought severity?, Plant Cell Environ., 33, 863-875, 2010.

Lin, Y.-S., Medlyn, B. E., Duursma, R. A., Prentice, I. C., Wang, H., Baig, S., Eamus, D., de Dios, V. R., Mitchell, P., Ellsworth, D. S., de Beeck, M. O., Wallin, G., Uddling, J., Tarvainen, L., Linderson, M.-L., Cernusak, L. A., Nippert, J. B., Ocheltree, T. W., Tissue, D. T., Martin-StPaul, N. K., Rogers, A., Warren, J. M., De Angelis, P., Hikosaka, K., Han, Q., Onoda, Y., Gimeno, T. E., Barton, C. V. M., Bennie, J., Bonal, D., Bosc, A., Low, M., Macinins-Ng, C., Rey, A., Rowland, L., Setterfield, S. A., TauszPosch, S., Zaragoza-Castells, J., Broadmeadow, M. S. J., Drake, J. E., Freeman, M., Ghannoum, O., Hutley, L. B., Kelly, J. W., Kikuzawa, K., Kolari, P., Koyama, K., Limousin, J.-M., Meir, P., Lola da Costa, A. C., Mikkelsen, T. N., Salinas, N., Sun, W., and Wingate, L.: Optimal stomatal behaviour around the world, Nature Clim. Change, 5, 459-464, 2015.

Lombardozzi, D. L., Bonan, G. B., Smith, N. G., Dukes, J. S., and Fisher, R. A.: Temperature acclimation of photosynthesis and respiration: A key uncertainty in the carbon cycle-climate feedback, Geophys. Res. Lett., 42, 8624-8631, 2015.

Long, S. P., Ainsworth, E. A., Rogers, A., and Ort, D. R.: Rising atmospheric carbon dioxide: plants FACE the future, Ann. Rev. Plant. Biol, 55, 591-628, 2004.

Maire, V., Martre, P., Kattge, J., Gastal, F., Esser, G., Fontaine, S., and Soussana, F.: The coordination of leaf photosynthesis links $\mathrm{C}$ and $\mathrm{N}$ fluxes in $\mathrm{C}_{3}$ plant species, PLos ONE, 7, e38245, doi:38310.31371/journal.pone.0038345, 2012.

Maire, V., Wright, I. J., Prentice, I. C., Batjes, N. H., Bhaskar, R., van Bodegom, P. M., Cornwell, W. K., Ellsworth, D., Niinemets, Ü., Ordonez, A., Reich, P. B., and Santiago, L. S.: Global effects of soil and climate on leaf photosynthetic traits and rates, Global Ecol. Biogeogr., 24, 706-717, 2015.

Makino, A. and Osmond, B.: Effects of nitrogen nutrition on nitrogen partitioning between chloroplasts and mitochondria in pea and wheat, Plant Physiol., 96, 355-362, 1991.

Maroco, J. P., Breia, E., Faria, T., Pereira, J. S., and Chaves, M. M.: Effects of long-term exposure to elevated $\mathrm{CO}_{2}$ and $\mathrm{N}$ fertilization on the development of photosynthetic capacity and biomass accumulation in Quercus suber L., Plant Cell Environ., 25, 105113, 2002.

Martin, B., Martensson, O., and Öquist, G.: Seasonal effects on photosynthetic electron transport and fluorescence properties in isolated chloroplasts of Pinus sylvestris, Physiol. Plantarum, 44, 102-109, 1978.

Mayer, D. G. and Butler, D. G.: Statistical validation, Ecol. Model., 68, 21-32, 1993.

McDowell, N.: Mechanisms linking drought, hydraulics, carbon metabolism, and vegetation mortality, Plant Physiol., 155, 10511059, 2011.

McMurtrie, R. E., Iversen, C. M., Dewar, R. C., Medlyn, B. E., Näsholm, T., Pepper, D. A., and Norby, R. J.: Plant root distributions and nitrogen uptake predicted by a hypothesis of optimal root foraging, Ecology and Evolution, 2, 1235-1250, 2012.

Medlyn, B. E., Badeck, F.-W., De Pury, D. G. G., Barton, C. V. M., Broadmeadow, M., Ceulemans, R., De Angelis, P., Forstreuter, 
M., Jach, M. E., Kellomäki, S., Laitat, E., Marek, M., Philippot, S., Rey, A., Strassemeyer, J., Laitinen, K., Liozon, R., Portier, B., Proberntz, P., Wang, K., and Jarvis, P. G.: Effects of elevated $\left[\mathrm{CO}_{2}\right]$ on photosynthesis in European forest species: a metaanalysis of model parameters, Plant Cell Environ., 22, 14751495, 1999.

Medlyn, B. E., Dreyer, E., Ellsworth, D., Forstreuter, M., Harley, P. C., Kirschbaum, M. U. F., Le Roux, X., Montpied, P., Strassemeyer, J., Walcroft, A., Wang, K., and Loustau, D.: Temperature response of parameters of a biochemically based model of photosynthesis. II. A review of experimental data, Plant Cell Environ., 25, 1167-1179, 2002a.

Medlyn, B. E., Loustau, D., and Delzon, S.: Temperature response of parameters of a biochemically based model of photosynthesis. I. Seasonal changes in mature maritime pine (Pinus pinaster Ait.), Plant Cell Environ., 25, 1155-1165, 2002b.

Medlyn, B. E., Robinson, B. A., Clement, R., and McMurtrie, R. E.: On the validation of models of forest $\mathrm{CO}_{2}$ exchange using eddy covariance data: some perils and pitfalls, Tree Physiol., 25, 839-857, 2005.

Medlyn, B. E., Duursma, R. A., Eamus, D., Ellsworth, D. A., Prentice, I. C., Barton, C. V. M., Crous, K. Y., De Angelis, P., Freeman, M., and Wingate, L.: Reconciling the optimal and empirical approaches to modelling stomatal conductance, Glob. Change Biol., 10, 1365-2486, 2011.

Meehl, G. A., Boer, G. J., Covey, C., Latif, M., and Stouffer, R. J.: The Coupled Model Intercomparison Project (CMIP), B. Am. Meteorol. Soc., 81, 313-318, 2000.

Miao, Z., Xu, M., Lathrop, R. G., and Wang, Y.: Comparison of the A-Cc curve fitting methods in determining maximum ribulose 1 5-bisphosphate carboxylase/oxygenase carboxylation rate, potential light saturated electron transport rate and leaf dark respiration, Plant Cell \& Environ., 32, 109-122, 2009.

Moorcroft, P. R., Hurtt, G. C., and Pacala, S. W.: A method for scaling vegetation dynamics: the ecosystem demography model (ED), Ecol. Monogr., 71, 557-586, 2001.

Moran, E. V., Hartig, F., and Bell, D. M.: Intraspecific trait variation across scales: implications for understanding global change responses, Glob. Change Biol., 22, 137-150, doi:10.1111/gcb.13000, 2016.

Niinemets, Ü. and Tenhunen, J. D.: A model separating leaf structural and biphysiological effects on carbon gain along light gradients for the shade-tolerant species Acer saccharum, Plant Cell Environ., 20, 845-866, 1997.

Oleson, K. W., Lawrence, D. M., Bonan, G. B., Drewniak, B., Huang, M., Koven, C. D., Levis, S., Li, F., Riley, W. J., Subin, Z. M., Swenson, S. C., Thornton, P. E., Bozbiyik, A., Fisher, R., Kluzek, E., Lamarque, J.-F., Lawrence, P. J., Leung, L. R., Lipscomb, W., Muszala, S., Ricciuto, D. M., Sacks, W., Sun, Y., Tang, J., and Yang, Z.-L.: Technical Description of version 4.5 of the Community Land Model (CLM), NCAR Technical Note NCAR/TN-503+STR, National Center for Atmospheric Research, Boulder, CO, 2013.

Öquist, G., Brunes, L., Hällgren, J.-E., Gezelius, K., Hallén, M., and Malmberg, G.: Effects of artificial frost hardening and winter stress on net photosynthesis, photosynthetic electron transport and RuBP carboxylase activity in seedlings of Pinus sylvestris, Physiol. Plantarum, 48, 526-531, 1980.
Prentice, I. C., Dong, N., Gleason, S. M., Maire, V., and Wright, I. J.: Balancing the costs of carbon gain and water transport: testing a new theoretical framework for plant functional ecology, Ecol. Lett., 17, 82-91, 2014.

Raddatz, T., Reick, C., Knorr, W., Kattge, J., Roeckner, E., Schnur, R., Schnitzler, K. G., Wetzel, R. G., and Jungclaus, J.: Will the tropical land biosphere dominate the climate-carbon cycle feedback during the twenty-first century?, Clim. Dynam., 29, 565574, 2007.

Reich, P. B. and Oleksyn, J.: Global patterns of plant leaf N and P in relation to temperature and latitude, Proc. Natl. Acad. Sci., 101, 11001-11006, 2004.

Reich, P. B., Kloeppel, B. D., Ellsworth, D., and Walters, M. B.: Different photosynthesis nitorgen relations in decidious hardwood and evergreen coniferous tree species, Oecologia, 104, 24-30, 1995.

Reich, P. B., Walters, M. B., Tjoelker, M. G., Vanderklein, D., and Buschena, C.: Photosynthesis and respiration rates depend on leaf and root morphology and nitrogen concentration in nine boreal tree species differing in relative growth rate, Funct. Ecol., 12, 395-405, 1998.

Riebeek, H.: The Carbon Cycle, NASA Earth Observatory, available at: http://earthobservatory.nasa.gov/Features/CarbonCycle/ (last access: 6 August 2015), 2011.

Ripullone, F., Grassi, G., Lauteri, M., and Borghetti, M.: Photosynthesis-nitrogen relationships: interpretation of different patterns between Pseudotsuga menziesii and Populus x euroamericana in a mini-stand experiment, Tree Physiol., 23, 137144, 2003.

Rogers, A.: The use and misuse of $\mathrm{V}_{\mathrm{c}, \max }$ in earth system models, Photosynt. Res., 119, 1-15, 2014.

Ryan, M. G.: Foliar maintenance respiration of subalpine and boral trees and shrubs in relation to nitrogen concentration, Plant Cell Environ., 18, 765-772, 1995.

Schaefer, K., Schwalm, C. R., Williams, C., Arain, M. A., Barr, A., Chen, J. M., Davis, K. J., Dimitrov, D., Hilton, T. W., Hollinger, D. Y., Humphreys, E., Poulter, B., Raczka, B. M., Richardson, A. D., Sahoo, A., Thornton, P., Vargas, R., Verbeeck, H., Anderson, R., Baker, I., Black, T. A., Bolstad, P., Chen, J., Curtis, P. S., Desai, A. R., Dietze, M., Dragoni, D., Gough, C., Grant, R. F., Gu, L., Jain, A., Kucharik, C., Law, B., Liu, S., Lokipitiya, E., Margolis, H. A., Matamala, R., McCaughey, J. H., Monson, R., Munger, J. W., Oechel, W., Peng, C., Price, D. T., Ricciuto, D., Riley, W. J., Roulet, N., Tian, H., Tonitto, C., Torn, M., Weng, E., and Zhou, X.: A model-data comparison of gross primary productivity: Results from the North American Carbon Program site synthesis, J. Geophys. Res.-Biogeosci., 117, G03010, doi:03010.01029/02012JG001960, 2012.

Schymanski, S. J., Sivapalan, M., Roderick, M. L., Hutley, L. B., and Beringer, J.: An optimality-based model of the dynamic feedbacks between natural vegetation and the water balance, Water Resour. Res., 45, W01412, doi:01410.01029/02008WR006841, 2009.

Sellers, P. J., Dickinson, R., Randall, D. A., Betts, A. K., Hall, F. G., Berry, J. A., Collatz, G. J., Denning, A. S., Mooney, H. A., Nobre, A. D., Sato, N., Field, C. B., and HendersonSellers, A.: Modeling the exchanges of energy, water, and carbon between continents and the atmosphere, Science, 275, 502-509, 1997. 
Sitch, S., Smith, B., Prentice, I. C., Arneth, A., Bondeau, A., Cramer, W., Kaplan, J. O., Levis, S., Lucht, W., Sykes, M. T., Thonicke, K., and Venevsky, S.: Evaluation of ecosystem dynamics, plant geography and terrestrail carbon cycling in the LPJ dynamic global vegetation model, Glob. Change Biol., 9, 161-185, 2003.

Smith, B., Prentice, I. C., and Sykes, M. T.: Representation of vegetation dynamics in the modelling of terrestrial ecosystems: comparing two contrasting approaches within European climate space, Global Ecol. Biogeogr., 10, 621-637, 2001.

Smith, E.: The influence of light and carbon dioxide on photosynthesis, General Physiology, 20, 807-830, 1937.

Song, Y. H., Ito, S., and Imaizumi, T.: Flowering time regulation: photoperiod- and temperature-sensing in leaves, Trends Plant Sci., 18, 575-583, 2013.

Spreitzer, R. J. and Salvucci, M. E.: Rubisco: structure, regulatory interactions, and possibilities for a better enzyme, Ann. Rev. Plant Bio., 53, 449-475, 2002.

Strand, M. and Öquist, G.: Effects of frost hardening, dehardening and freezing trees on in vivo fluorescence of seedlings of Scots pine (Pinus sylvestris L.), Plant Cell Environ., 11, 231238, 1988.

Taylor, K. E., Stouffer, R. J., and Meehl, G. A.: An overview of CMIP5 and the experiment design, B. Am. Meteorol. Soc., 93, 485-498, 2013.

Thomas, R. Q. and Williams, M.: A model using marginal efficiency of investment to analyze carbon and nitrogen interactions in terrestrial ecosystems (ACONITE Version 1), Geosci. Model Dev., 7, 2015-2037, doi:10.5194/gmd-7-2015-2014, 2014.

Valladares, F., Wright, S. J., Lasso, E., Kitajima, K., and Pearcy, R. W.: Plastic phenotypic response to light of 16 congeneric shrubs from a Panamanian rainforest, Ecology, 81, 1925-1936, 2000.

Van Oijen, M., Schapendonk, A., and Hoglind, M.: On the relative magnitudes of photosynthesis, respiration, growth and carbon storage in vegetation, Ann. Bot.-London, 105, 793-797, 2010.

Verheijen, L. M., Brovkin, V., Aerts, R., Bönisch, G., Cornelissen, J. H. C., Kattge, J., Reich, P. B., Wright, I. J., and van Bodegom, P. M.: Impacts of trait variation through observed trait-climate relationships on performance of an Earth system model: a conceptual analysis, Biogeosciences, 10, 5497-5515, doi:10.5194/bg10-5497-2013, 2013.

Verheijen, L. M., Aerts, R., Brovkin, V., Cavender-Bares, J., Cornelissen, J. H. C., Kattge, J., and van Bodegom, P. M.: Inclusion of ecologically based trait variation in plant functional types reduces the projected land carbon sink in an earth system model, Glob. Change Biol., 21, 3074-3086, 2015.

Vrugt, J. A., ter Braak, C. J. F., Clark, M. P., Hyman, J. M., and Robinson, B. A.: Treatment of input uncertainty in hydrologic modeling: Doing hydrology backward with Markov chain Monte Carlo simulation, Water Resour. Res., 44, W00B09, doi:10.1029/2007WR006720, 2008.

Vrugt, J. A., ter Braak, C. J. F., Diks, C. G. H., Robinson, B. A., Hyman, J. M., and Higdon, D.: Accelerating Markov Chain Monte Carlo Simulation by Differential Evolution with Self-Adaptive Randomized Subspace Sampling, Int. J. Nonlin. Sci. Num., 10, 273-290, 2009.
Walker, A. P., Beckerman, A. P., Gu, L., Kattge, J., Cernusak, L. A., Domingues, T. F., Scales, J. C., Wohlfahrt, G., Wullschleger, S. D., and Woodward, F. I.: The relationship of leaf photosynthetic traits - Vcmax and Jmax - to leaf nitrogen, leaf phosphorus, and specific leaf area: a meta-analysis and modeling study, Ecology and Evolution, 4, 3218-3235, 2014.

Wang, Y. P., Law, R. M., and Pak, B.: A global model of carbon, nitrogen and phosphorus cycles for the terrestrial biosphere, Biogeosciences, 7, 2261-2282, doi:10.5194/bg-7-2261-2010, 2010.

White, M. A., Thornton, P. E., Running, S. W., and Nemani, R. R.: Parameterization and sensitivity analysis of the BIOME-BCG terrestrial ecosystem model: net primary production controls, Earth Interact., 4, 1-85, 2000.

Whitley, R. J., Catriona, M. O., Macinnis-Ng, C., Hutley, L. B., Beringer, J., Zeppel, M., Williams, M., Taylor, D., and Eamus, D.: Is productivity of mesic savannas light limited or water limited? Results of a simulation study, Glob. Change Biol., 17, 3130-3149, 2011.

Wieder, W. R., Cleveland, C. C., Lawrence, D. M., and Bonan, G. B.: Effects of model structural uncertainty on carbon cycle projections: biological nitrogen fixation as a case study, Environ. Res. Lett., 10, 044016, doi:10.1088/1748-9326/1010/1084/0440, 2015.

Wilson, K. B., Baldocchi, D. D., and Hanson, P. J.: Leaf age affects the seasonal pattern of photosynthetic capacity and net ecosystem exchange of carbon in a deciduous forest, Plant Cell Environ., 24, 571-583, 2001.

Wright, I. J., Reich, P. B., Westoby, M., Ackerly, D. D., Baruch, Z., Bongers, F., Cavender-Bares, J., Chapin, T., Cornelissen, J. H. C., Diemer, M., Flexas, J., Garnier, E., Groom, P. K., Gulias, J., Hikosaka, K., Lamont, B. B., Lee, T. D., Lee, W., Lusk, C. H., Midgley, J. J., Navas, M.-L., Niinemets, Ü., Olesksyn, J., Osada, N., Poorter, H., Poot, P., Prior, L., Pyankov, V. I., Roumet, C., Thomas, S. C., Tjoelker, M. G., Veneklaas, E. J., and Villar, R.: The worldwide leaf economics spectrum, Nature, 428, 821-827, 2004.

Wullschleger, S. D.: Biochemical limitations to carbon assimilation in $C_{3}$ plants: a retrospective analysis of $A / C_{i}$ curves from 109 species, J. Exp. Bot. 44, 907-920, 1993.

Xu, C., Fisher, R., Wullschleger, S. D., Wilson, C. J., Cai, M., and McDowell, N.: Toward a mechanistic modeling of nitrogen limitation on vegetation dynamics, PLos ONE, 7, e37914, doi:10.1371/journal.pone.0037914, 2012.

Xu, L. and Baldocchi, D. D.: Seasonal trends in photosynthetic parameters and stomatal conductance of blue oak (Quercus douglasii) under prolonged summer drought and high temperature, Tree Physiol., 23, 865-877, 2003.

Yamori, W., Suzuki, K., Noguchi, K. O., Nakai, M., and Terashima, I.: Effects of Rubisco kinetics and Rubisco activation state on the temperature dependence of the photosynthetic rate in spinach leaves from contrasting growth temperatures, Plant Cell Environ., 29, 1659-1670, 2006. 